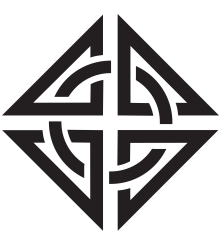

SCIENTIA
Sharif University of Technology

Scientia Iranica

Transactions E: Industrial Engineering

http://scientiairanica.sharif.edu

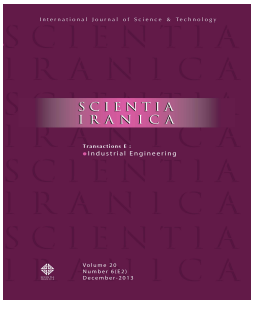

\title{
Applying SVSSI sampling scheme to np-chart to decrease the time of detecting shifts using Markov chain approach and Monte Carlo simulation
}

\author{
M. Shojaee ${ }^{a}$, S. Jafarian-Namin ${ }^{\mathrm{b}, *}$, S.M.T. Fatemi Ghomi ${ }^{\mathrm{c}}$, D.M. Imani ${ }^{\mathrm{a}}$, \\ A. Faraz ${ }^{\text {, }}$, and M.S. Fallahnezhad ${ }^{\text {b }}$ \\ a. Department of Industrial Engineering, Iran University of Science and Technology, Tehran, Iran. \\ b. Department of Industrial Engineering, Yazd University, Yazd, Iran. \\ c. Department of Industrial Engineering, Amirkabir University of Technology, Tehran, Iran. \\ d. Logistikum, University of Applied Sciences Upper Austria, Steyr, Austria.
}

Received 12 January 2019; received in revised form 20 August 2020; accepted 2 November 2020

\section{KEYWORDS}

SVSSI scheme;

Np control chart;

Average time to

signal;

Adjusted average time

to signal;

Markov chain.

\begin{abstract}
One of the main criteria for judging the power of control charts is their ability to perform fast detection of deviations and shifts in the process. Average Time to Signal (ATS) and Adjusted Average Time to Signal (AATS) are among such criteria calculated under a certain state and assumption. Several studies have shown that based on the idea of variable design for control charts and by demarcating the limits between safe and unsafe regions, quick discovery of shifts is facilitated and sensitivity to small changes increases. In this paper, a new variable sampling scheme with three sample sizes and two different sampling intervals, called SVSSI, is developed to increase the efficiency of the control chart $\mathrm{np}$. Through various numerical examples, the performance of this scheme is evaluated by calculating ATS and AATS values through the application of Markov chain method. Monte Carlo simulation method is used to validate the results of Markov chain method of SVSSI sampling scheme. In comparison with other schemes, SVSSI exhibits better performance in all conditions.
\end{abstract}

(C) 2022 Sharif University of Technology. All rights reserved.

\section{Introduction}

Control chart is the most important tool to control processes during production. Average Run Length

\footnotetext{
*. Corresponding author.

E-mail addresses: M_shojaie@ind.iust.ac.ir (M. Shojaee); Samrad.jafarian@stu.yazd.ac.ir (S.Jafarian-Namin); Fatemi@aut.ac.ir (S.M.T. Fatemi Ghomi);

Imanim@iust.ac.ir(D.M.Imani); Alireza.faraz@fh-steyr.at (A.Faraz); Fallahnezhad@yazd.ac.ir (M.S.Fallahnezhad)
}

doi: $10.24200 /$ sci. 2020.52677 .2833
(ARL), Average Time to Signal (ATS), and Adjusted Average Time to Signal (AATS) are well-known criteria to measure the performance of control charts. The ARL criterion is applied only in cases where the sampling interval is supposed to be fixed during the process; otherwise, ATS or AATS criterion must be used. Based on the ARL, several studies have been conducted on the Variable Sample Size (VSS) method in which only the sample size varies. Upon comparing VSS method with the fixed sampling method by Teoh et al. [1], Muhammad et al. [2], Annadi et al. [3], Amiri et al. [4], Aparisi [5], and Yeong et al. [6], different 
states for various control charts have been carried out; accordingly, positive results have been achieved using VSS. Due to the performance of the VSS sampling method, design of variable control charts has attracted much attention. Further, studies have mostly been conducted to shorten the time of signal by ATS and AATS criteria on other variable sampling methods such as VSI (with Variable Sampling Interval) and VSSI (with Variable Sample Size and Sampling Interval); (see e.g. [7-10]). ATS and AATS are comprehensive and well-known criteria that can be used to evaluate any type of sampling methods for control charts. Ultimately, Costa and Rahim [11] presented the Full Adaptive (FA) or Variable Parameter (VP) sampling scheme. The main difference between the FA sampling scheme and other sampling schemes is that in the case of the former, in addition to the variable values of the sample size and sampling interval, the control and warning limits are also considered variable. To study the details of designing this sampling scheme, (see [1218]).

ATS, which represents the mean time of detecting the change from the moment of the occurrence of the shift in the process mean to the moment that control chart signals, was applied by Prabhu et al. [17] to evaluate the VSSI sampling method for control chart $X$. This criterion, calculated based on the concepts of the Markov chain and the transfer between different states, was also used by Aparisi and Haro [18] to measure the performance of the VSI sampling method for the $T^{2}$ Hotelling chart. In their study, for different shifts, the ATS values for VSI and fixed sampling methods were calculated and compared. Moreover, taking into account the same assumptions about the ATS calculation, Aparisi and Haro [19] evaluated VSSI and other sampling methods for the $T^{2}$ Hotelling chart based on the lowest amount of ATS. In order to monitor simple linear profiles, Kazemzadeh et al. [20] provided a complete study on the reduction of ATS and other statistical indices by fixed, VSS, and VSI sampling methods with different shift values and input parameters. Luo and $\mathrm{Wu}$ [21] as well as Wu and Luo [22] explored in separate studies the effects of variable sampling methods on the np control chart by numerical examples and considered ATS in different states. They provided a statistical model aimed at reducing ATS to assess VSS, VSI, VSSI and fix sampling methods. Similar researches including Abdella et al. [23], Chen and Hsieh [24], Lee and Khoo [25], Zhang et al. [26], Chen et al. [27] and Castagliola et al. [28] performed ATS-based evaluation for the results.

ATS criterion is based on the assumption that the process starts from out-of-control state. However, Costa [29] proposed another approach to analyze the results assuming that the process begins from the incontrol state, and the difference between the duration of a production cycle and in-control time indicates the duration of change detection, i.e., AATS. They calculated AATS in different states for the variable $X$ control chart. Faraz et al. [30] presented the differences between ATS and AATS in their research and then, conducted their assessments for $\mathrm{VSI}-T^{2}$ control chart based on AATS. Accordingly, although the application of ATS simplifies and reduces the volume of calculations, AATS can be more realistic for assessments because it is usually in control before initiation of any process. Lin and Chou [31] considered both AATS and ATS for assessing the results. They analyzed the influence of using VSS, VSI, and VSSI sampling methods on the $X$ control chart under normal and non-normal conditions based on AATS and ATS. Taking into account the AATS criteria, Katebi and Moghadam [13] implemented a comprehensive study on the performances of VSS, VSI, VSSI, FA, and fixed sampling schemes. According to the obtained results, the relative superiority of the FA scheme was evident compared to other schemes. In recent years, AATS has been of greater interest to researchers (e.g., refer to [32-34]).

In all the mentioned researches and other similar works such as Faraz and Saniga [35], Mahadik [36], Khaw et al. [37], and Saha et al. [38], the application of VSSI and FA sampling methods to designing control charts indicates better performance. An important point to notice is whether the performance of control charts can be further improved or not. Faraz and Parsian [39] proposed the idea of using Double Warning Lines (DWL) for the $T^{2}$ control chart. The DWL sampling method is similar to the VSSI method, except for using two separate warning lines for sample sizes and sampling intervals to monitor the process. Despite being more complicated, it has a better performance than VSSI. Since then, the economic and economicstatistical performances of using this sampling method were investigated by Faraz et al. [40] and Faraz and Saniga [41].

Mahadik and Shirke $[42,43]$ evaluated the SVSSI sampling method for the $X$ and $T^{2}$ control charts in separate studies. Their proposed method, which is simpler and more practical than DWL, improved the performance of the $X$ and $T^{2}$ control charts and led to better results than VSSI and FA schemes. Furthermore, in terms of costs and by taking into account the statistical criteria, Katebi et al. [44] assessed SVSSI sampling method for the $T^{2}$ control chart. Their results were satisfactory and costs were reduced by using SVSSI method in comparison to other methods.

Despite the widespread use of $n p$ control chart in the literature, the current research introduces some contributions in the following paragraphs.

For the characteristics of $n p$ control charts, mostly two variables have been considered for their simplicity. 
However, in this paper, the scheme SVSSI presented for the $n p$ control chart provides three different sample sizes and two different sampling intervals depending on the process situations. Besides being easy to understand and implement, this scheme is superior to the other sampling schemes in terms of performance.

Since the ARL criterion is not applicable because of time variability, two important criteria for checking the time of signal, namely AATS and ATS, are presented and fully discussed in this paper. Comprehensive evaluations based on ATS and AATS are provided. Accordingly, by improving these criteria through the proposed sampling algorithm, better performance of the control chart, reduction of detection time, avoiding the production of further defective items, and decrease in costs are expected.

In Section 2, the method of sampling is introduced. Statistical criteria are reviewed in Section 3. By providing various numerical examples in Section 4, variable sampling methods are evaluated and compared. Finally, conclusions are made along with suggestions for the future.

\section{Designing SVSSI-np control chart}

In the SVSSI sampling method, three sample sizes $n_{1}$, $n_{2}$, and $n_{3}$ and two sampling intervals $h_{1}$ and $h_{2}$ are used, assuming that $n_{1}<n_{2}<n_{3}$ and $h_{1}<h_{2}$. To determine the time of change in sample size and sampling interval of subgroups, two warning limits $W_{i}^{1}$ and $W_{i}^{2}$ and one control limit $K_{i}$ are used. Depending on the size of the sample, the values of these limits vary at different $i$ values. The SVSSI sampling method is briefly described as follows:

$$
\begin{cases}n_{1}, h_{1} & 0 \leq n p<W_{i}^{1} \\ n_{2}, h_{2} & W_{i}^{1} \leq n p<W_{i}^{2} \\ n_{3}, h_{2} & W_{i}^{2} \leq n p<K_{i}\end{cases}
$$

Therefore, if the value of the statistic for the $(i-1)$ th subgroup be in the first region $\left(0 \leq n p<W_{i}^{1}\right)$, there is no reason for a change in the process to occur. Thus, the $i$ th subgroup with small sample size $n_{1}$ and longer sampling interval $h_{1}$ is plotted on the chart. If the value of the statistic be in the second region $\left(W_{i}^{1} \leq n p<W_{i}^{2}\right)$, then it is likely that a change in the mean will occur. Therefore, it is possible to signal a warning by the chart in the next subgroup. To have more control over the process, the $i$ th subgroup with the size of $n_{2}$ is taken after the interval of $h_{2}$. Finally, if the statistic be in the third region $\left(W_{i}^{2} \leq n p<K_{i}\right)$, then it is more likely that a change in the mean of the process will occur. Hence, the next sample is taken with the increased size of $n_{3}$ after the interval of $h_{2}$. In Figure 1, the SVSSI-np control chart is shown based on the description given above.

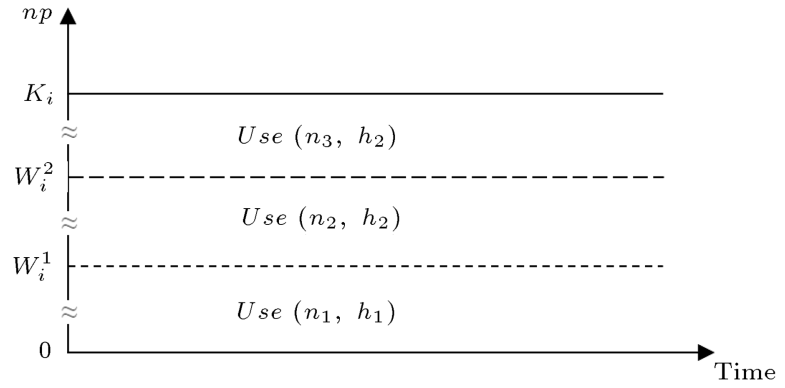

Figure 1. SVSSI-np control chart.

The limits of the warning and control of the SVSSI-np chart are calculated as $n_{i} p_{0}+r\left(n_{i} p_{0}(1-\right.$ $\left.\left.p_{0}\right)\right)^{0.5}$, where $r$ is the coefficient of control and warning limit and $p_{0}$ represents the mean of the process in the in-control state (the parameters are defined in Appendix A). At each sampling time, the occurrence probability for one of the following scenarios exists:

1. If $0 \leq n p<W_{i}^{1}$, the next sample with a size of $n_{1}$ is taken after the interval of $h_{1}$;

2. If $W_{i}^{1} \leq n p<W_{i}^{2}$, the next sample with a size of $n_{2}$ is taken after the interval of $h_{2}$; and

3. If $W_{i}^{2} \leq n p<K_{i}$, the next sample with a size of $n_{3}$ is taken after the interval of $h_{2}$.

Furthermore, the occurrence probability for the fourth state should be considered in which $n p \geq K_{i}$. In this state, the control chart signals that the process is out of control. Accordingly, the process is stopped for further investigations. If the process is identified to be in control, this signal is considered incorrect. Otherwise, corrective actions are taken to find the cause of change, fix it, and thus, restore the process. Since the design of the control chart SVSSI- $n p$ is based on the concepts of the Markov chain, according to Fallahnezhad et al. [45] and Faraz and Saniga [35], this state can be regarded as the absorbing state in Markov chains.

\section{Calculation of efficiency}

In this section, statistical well-known criteria that can be used to evaluate any types of sampling schemes for control charts are reviewed.

\subsection{AATS}

As stated, the AATS criterion is based on the assumption that the process begins from the in-control state. According to the scenarios described in Section 2, all of them can be in-control or out-of-control. Thus, the occurrence of eight states is probable at each sampling of the process. The change of state or the probability of transform between different states using the properties of the Markov chain is shown in this section with $p_{i j}$. According to Faraz and Saniga [35], $p_{i j}$ values can be defined as follows: 


$$
\begin{aligned}
p_{11} & =\operatorname{Pr}(1 \rightarrow 1)=\operatorname{Pr}\left(n_{1}, h_{1}, 0 \leq n p<W_{1}^{1}\right) \\
& =F\left(n_{1}, W_{1}^{1}, p_{0}\right) \times \exp \left(-\lambda h_{1}\right), \\
p_{16} & =\operatorname{Pr}(1 \rightarrow 6)=\operatorname{Pr}\left(n_{1}, h_{1}, W_{1}^{1} \leq n p<W_{1}^{2}\right) \\
& =\left(F\left(n_{1}, W_{1}^{2}, p_{1}\right)-F\left(n_{1}, W_{1}^{1}, p_{1}\right)\right) \\
& \times\left(1-\exp \left(-\lambda h_{1}\right)\right), \\
p_{28} & =\operatorname{Pr}(2 \rightarrow 8)=\operatorname{Pr}\left(n_{2}, h_{2}, K_{2} \leq n p\right) \\
& =\left(1-F\left(n_{2}, K_{2}, p_{1}\right)\right) \times\left(1-\exp \left(-\lambda h_{2}\right)\right), \\
p_{32} & =\operatorname{Pr}(3 \rightarrow 2)=\operatorname{Pr}\left(n_{3}, h_{2}, W_{3}^{1} \leq n p<W_{3}^{2}\right) \\
& =\left(F\left(n_{3}, W_{3}^{2}, p_{0}\right)-F\left(n_{3}, W_{3}^{1}, p_{0}\right)\right) \\
& \times \exp \left(-\lambda h_{2}\right) .
\end{aligned}
$$

The $n p$ control chart based on the Binomial distribution plots the number of defective items in the sample. Therefore, $F$ represents the cumulative distribution function of Binomial in calculating each $p_{i j}$. One of the main assumptions of this research in obtaining AATS, which is based on Costa [29] and Faraz et al. [30], is to consider the occurrence of the deviation according to Poisson distribution at a rate of $\lambda$ per time unit. Thus, the time interval between consecutive occurrences of deviations follows exponential distributions with parameter $\lambda$. As another main assumption, only one assignable cause leads to shifting the mean of the process from $p_{0}$ to $p_{1}$. The value of $p_{1}$ for the shift size of $r$ is obtained as follows:

$$
p_{1}=p_{0}+r \sqrt{p_{0}\left(1-p_{0}\right)} .
$$

Accordingly, the calculations of all $p_{i j}$ 's for a Markov chain with seven transition states and one absorbing state are given below (the probability of transforming from an out-of-control state into in-control states and the probability of transforming from an absorbing state into other states is supposed to be zero):

$$
\begin{aligned}
p_{11} & =F\left(n_{1}, W_{1}^{1}, p_{0}\right) \times \exp \left(-\lambda h_{1}\right), \\
p_{12} & =\left(F\left(n_{1}, W_{1}^{2}, p_{0}\right)-F\left(n_{1}, W_{1}^{1}, p_{0}\right)\right) \\
& \times \exp \left(-\lambda h_{1}\right), \\
p_{13} & =\left(F\left(n_{1}, K_{1}, p_{0}\right)-F\left(n_{1}, W_{1}^{2}, p_{0}\right)\right) \\
& \times \exp \left(-\lambda h_{1}\right), \\
p_{14} & =\left(1-F\left(n_{1}, K_{1}, p_{0}\right)\right) \times \exp \left(-\lambda h_{1}\right), \\
p_{15} & =F\left(n_{1}, W_{1}^{1}, p_{1}\right) \times\left(1-\exp \left(-\lambda h_{1}\right)\right),
\end{aligned}
$$

$$
\begin{aligned}
& p_{16}=\left(F\left(n_{1}, W_{1}^{2}, p_{1}\right)-F\left(n_{1}, W_{1}^{1}, p_{1}\right)\right) \\
& \times\left(1-\exp \left(-\lambda h_{1}\right)\right), \\
& p_{17}=\left(F\left(n_{1}, K_{1}, p_{1}\right)-F\left(n_{1}, W_{1}^{2}, p_{1}\right)\right) \\
& \times\left(1-\exp \left(-\lambda h_{1}\right)\right), \\
& p_{18}=\left(1-F\left(n_{1}, K_{1}, p_{1}\right)\right) \times\left(1-\exp \left(-\lambda h_{1}\right)\right), \\
& p_{21}=F\left(n_{2}, W_{2}^{1}, p_{0}\right) \times \exp \left(-\lambda h_{2}\right), \\
& p_{22}=\left(F\left(n_{2}, W_{2}^{2}, p_{0}\right)-F\left(n_{2}, W_{2}^{1}, p_{0}\right)\right) \\
& \times \exp \left(-\lambda h_{2}\right), \\
& p_{23}=\left(F\left(n_{2}, K_{2}, p_{0}\right)-F\left(n_{2}, W_{2}^{2}, p_{0}\right)\right) \\
& \times \exp \left(-\lambda h_{2}\right) \\
& p_{24}=\left(1-F\left(n_{2}, K_{2}, p_{0}\right)\right) \times \exp \left(-\lambda h_{2}\right), \\
& p_{25}=F\left(n_{2}, W_{2}^{1}, p_{1}\right) \times\left(1-\exp \left(-\lambda h_{2}\right)\right), \\
& p_{26}=\left(F\left(n_{2}, W_{2}^{2}, p_{1}\right)-F\left(n_{2}, W_{2}^{1}, p_{1}\right)\right) \\
& \times\left(1-\exp \left(-\lambda h_{2}\right)\right), \\
& p_{27}=\left(F\left(n_{2}, K_{2}, p_{1}\right)-F\left(n_{2}, W_{2}^{2}, p_{1}\right)\right) \\
& \times\left(1-\exp \left(-\lambda h_{2}\right)\right), \\
& p_{28}=\left(1-F\left(n_{2}, K_{2}, p_{1}\right)\right) \times\left(1-\exp \left(-\lambda h_{2}\right)\right), \\
& p_{41}=p_{31}=F\left(n_{3}, W_{3}^{1}, p_{0}\right) \times \exp \left(-\lambda h_{2}\right), \\
& p_{42}=p_{32}=\left(F\left(n_{3}, W_{3}^{2}, p_{0}\right)-F\left(n_{3}, W_{3}^{1}, p_{0}\right)\right) \\
& \times \exp \left(-\lambda h_{2}\right) \\
& p_{43}=p_{33}=\left(F\left(n_{3}, K_{3}, p_{0}\right)-F\left(n_{3}, W_{3}^{2}, p_{0}\right)\right) \\
& \times \exp \left(-\lambda h_{2}\right), \\
& p_{44}=p_{34}=\left(1-F\left(n_{3}, K_{3}, p_{0}\right)\right) \times \exp \left(-\lambda h_{2}\right), \\
& p_{45}=p_{35}=F\left(n_{3}, W_{3}^{1}, p_{1}\right) \times\left(1-\exp \left(-\lambda h_{2}\right)\right) \text {, } \\
& p_{46}=p_{36}=\left(F\left(n_{3}, W_{3}^{2}, p_{1}\right)-F\left(n_{3}, W_{3}^{1}, p_{1}\right)\right) \\
& \times\left(1-\exp \left(-\lambda h_{2}\right)\right), \\
& p_{47}=p_{37}=\left(F\left(n_{3}, K_{3}, p_{1}\right)-F\left(n_{3}, W_{3}^{2}, p_{1}\right)\right) \\
& \times\left(1-\exp \left(-\lambda h_{2}\right)\right), \\
& p_{48}=p_{38}=\left(1-F\left(n_{3}, K_{3}, p_{1}\right)\right) \\
& \times\left(1-\exp \left(-\lambda h_{2}\right)\right),
\end{aligned}
$$




$$
\begin{aligned}
& p_{55}=F\left(n_{1}, W_{1}^{1}, p_{1}\right), \\
& p_{56}=F\left(n_{1}, W_{1}^{2}, p_{1}\right)-F\left(n_{1}, W_{1}^{1}, p_{1}\right), \\
& p_{57}=F\left(n_{1}, K_{1}, p_{1}\right)-F\left(n_{1}, W_{1}^{2}, p_{1}\right), \\
& p_{58}=1-F\left(n_{1}, K_{1}, p_{1}\right), \\
& p_{65}=F\left(n_{2}, W_{2}^{1}, p_{1}\right) \\
& p_{66}=F\left(n_{2}, W_{2}^{2}, p_{1}\right)-F\left(n_{2}, W_{2}^{1}, p_{1}\right), \\
& p_{67}=F\left(n_{2}, K_{2}, p_{1}\right)-F\left(n_{2}, W_{2}^{2}, p_{1}\right), \\
& p_{68}=1-F\left(n_{2}, K_{2}, p_{1}\right), \\
& p_{75}=F\left(n_{3}, W_{3}^{1}, p_{1}\right), \\
& p_{76}=F\left(n_{3}, W_{3}^{2}, p_{1}\right)-F\left(n_{3}, W_{3}^{1}, p_{1}\right), \\
& p_{77}=F\left(n_{3}, K_{3}, p_{1}\right)-F\left(n_{3}, W_{3}^{2}, p_{1}\right), \\
& p_{78}=1-F\left(n_{3}, K_{3}, p_{1}\right), \\
& p_{88}=1 .
\end{aligned}
$$

For more information on calculating transmission states for other variable control charts such as VSS, VSI, VSSI, and FA, the reader(s) can refer to Luo and $\mathrm{Wu}$ [21], Fallahnezhad et al. [45], Katebi and Moghadam [13], Faraz et al. [30], and Faraz and Saniga [35].

Therefore, the AATS based on the Markov chain approach is calculated as follows:

$$
\begin{aligned}
A A T S & =B \times(I-Q)^{-1} \times\left(h_{1}, h_{2}, h_{2}, h_{2}, h_{1}, h_{2}, h_{2}\right)^{\prime} \\
& -\frac{1}{\lambda},
\end{aligned}
$$

where $1 / \lambda$ is the mean of exponential distribution, which indicates the duration of in-control state for the process. $B$ is a vector of initial probabilities, which is recommended to avoid potential problems at the start, apply more control over the process, and start the sampling of the process from the state between the last warning threshold and the control limit (see [44-46]). Therefore, the vector $B$ is considered as $(0,0,1,0,0,0,0)$. Moreover, $I$ is an identity matrix of degree 7 and $Q$ is calculated as follows:

$$
Q=\left[\begin{array}{ccccccc}
p_{11} & p_{12} & p_{13} & p_{14} & p_{15} & p_{16} & p_{17} \\
p_{21} & p_{22} & p_{23} & p_{24} & p_{25} & p_{26} & p_{27} \\
p_{31} & p_{32} & p_{33} & p_{34} & p_{35} & p_{36} & p_{37} \\
p_{41} & p_{42} & p_{43} & p_{44} & p_{45} & p_{46} & p_{47} \\
0 & 0 & 0 & 0 & p_{55} & p_{56} & p_{57} \\
0 & 0 & 0 & 0 & p_{65} & p_{66} & p_{67} \\
0 & 0 & 0 & 0 & p_{75} & p_{76} & p_{77}
\end{array}\right]
$$

As can be seen, the matrix $Q$ contains all states of transitions except for the transition to absorbing state.

\section{2. $A T S$}

The major difference in calculation of ATS compared to AATS is in assumption of the process beginning 'in-control' or 'out-of-control' conditions. In the calculation of this criterion, according to Faraz et al. [30], it is assumed that the process starts from the out-of-control state $(d>0)$. Accordingly, only the occurrence probability for four states in the out-ofcontrol state can be defined for the process. In this section, the probability of transition between different states, shown by $p_{i j}^{d}$, is obtained as follows:

$$
\begin{aligned}
& p_{11}^{d}=p_{55}, \quad p_{21}^{d}=p_{65}, \quad p_{31}^{d}=p_{75}, \\
& p_{12}^{d}=p_{56}, \quad p_{22}^{d}=p_{66}, \quad p_{32}^{d}=p_{76}, \\
& p_{13}^{d}=p_{57}, \quad p_{23}^{d}=p_{67}, \quad p_{33}^{d}=p_{77}, \\
& p_{14}^{d}=p_{58}, \quad p_{24}^{d}=p_{68}, \quad p_{34}^{d}=p_{78}, \quad p_{44}^{d}=p_{88},
\end{aligned}
$$

and:

$$
A T S=B^{d} \times\left(I^{d}-Q^{d}\right)^{-1} \times\left(h_{1}, h_{2}, h_{2}\right)^{\prime},
$$

where $B^{d}$ is the initial probability vector when beginning the process from the out-of-control state and is equal to $(0,0,1)$. Here, the start of the process is also considered to be between the last warning threshold and the control limit. $I^{d}$ is an identity matrix of degree 3 and $Q^{d}$ is described as follows:

$$
Q^{d}=\left[\begin{array}{lll}
p_{11}^{d} & p_{12}^{d} & p_{13}^{d} \\
p_{21}^{d} & p_{22}^{d} & p_{23}^{d} \\
p_{31}^{d} & p_{32}^{d} & p_{33}^{d}
\end{array}\right]
$$

\section{Numerical examples and comparisons}

In this section, the performance of different sampling methods is studied based on both AATS and ATS. For each criterion, the results are shown in three separate tables based on different values of the fixed sample size $\left(n_{0}\right)$ and the fixed sampling interval $\left(h_{0}\right)$. In each table, the studies are performed based on five different values of $0.03,0.05,0.08,0.12$, and 0.18 for $p_{0}$ and six different values of $0.05,0.10,0.30,0.50,0.70$, and 0.90 for $d$, respectively. Given that: (1) The shifts are usually considered up to 8 hours and (2) The time intervals less than 0.1 in practice can be problematic because the process should be allowed to produce $n$ unit within a short time $h_{2}$; the values of sampling intervals range from 0.1 to 8 . Moreover, the range of sample sizes is considered between 1 and 50. In Table 1, the approach to determining the values of sample sizes and sample intervals is given for the SVSSI-np control chart.

In this research, the optimal values of AATS and ATS for different states are obtained by searching among different values of sample sizes and sampling intervals in the space of the desired charts. In other 
Table 1. The ranges of sample size and sampling interval for SVSSI-np control chart.

\begin{tabular}{cccc}
\hline & Min & Max & Step \\
\hline$n_{1}$ & 1 & $n_{0}-1$ & 1 \\
$n_{2}$ & $n_{1}+1$ & $n_{3}-1$ & 1 \\
$n_{3}$ & $n_{0}+1$ & 50 & 1 \\
$h_{1}$ & $h_{0}$ & 8 & 0.1 \\
$h_{2}$ & 0.1 & $h_{0}-0.1$ & 0.1 \\
\hline
\end{tabular}

words, the initial parameters for which the given criterion has the lowest value have been obtained. Then, at these points and for the obtained initial parameters, the optimal values of the given criterion are calculated in each step so that the comparison between different sampling methods can be possible. The results of the optimal values of AATS and ATS in all the calculations presented are based on the level parameter $(\lambda)$ of 0.05 and the coefficients $(r)$ of 1 , 2 , and 3 , which are considered for $K_{i}, W_{i}^{2}$, and $W_{i}^{1}$, respectively. Therefore, the optimal AATS and ATS values of different sampling methods along with the optimal parameters of the SVSSI sampling method are presented in Tables 2-4 and Tables 5-7, respectively. More information on the computation of AATS and ATS can be found in Appendix B.

As shown, comprehensive investigations of different sampling methods were provided based on AATS and ATS. According to the results in Tables 2-7, use of VSS, VSI, and VSSI sampling schemes improved the performance of the $n p$ control chart in detecting changes, among which the VSSI sampling scheme exhibits better performance. Changing the fixed control limits of the VSSI scheme to the variable control limits of the FA scheme significantly reduced AATS and ATS values. This is compatible with the results previously published by Katabi and Moghaddam [13]. Although it brings greater complexity when $K_{1} \neq K_{2}$ changes in the FA scheme, the obtained results of AATS and ATS show a decrease in both.

Furthermore, it is obvious that SVSSI sampling method, compared to the FA scheme, detects the shifts in the process in a shorter time. Generally, comparison of the SVSSI sampling method with other sampling methods indicates its superiority in most cases. Therefore, use of three sample sizes and two sampling intervals in the SVSSI scheme along with variable warning and control limits has greater impact on improving the detection speed of shifts in the $n p$ control chart than other schemes.

For more investigations, Monte Carlo simulation method is used to evaluate the results of Markov method of SVSSI sampling scheme. The simulation method is applied to approximately calculate ATS values by generating random data from Binomial

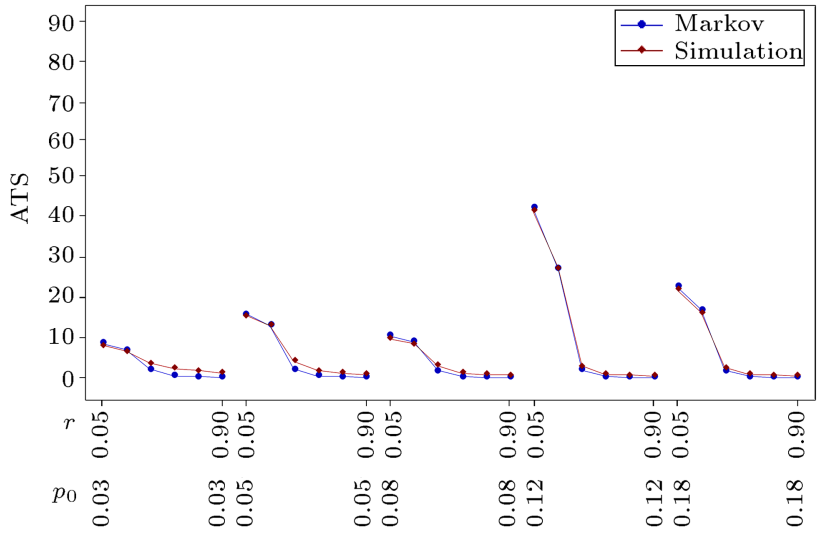

Figure 2. Comparing the optimal results of ATS obtained by Markov and simulation methods for SVSSI-np control chart when $n_{0}=4$ and $h_{0}=1$.

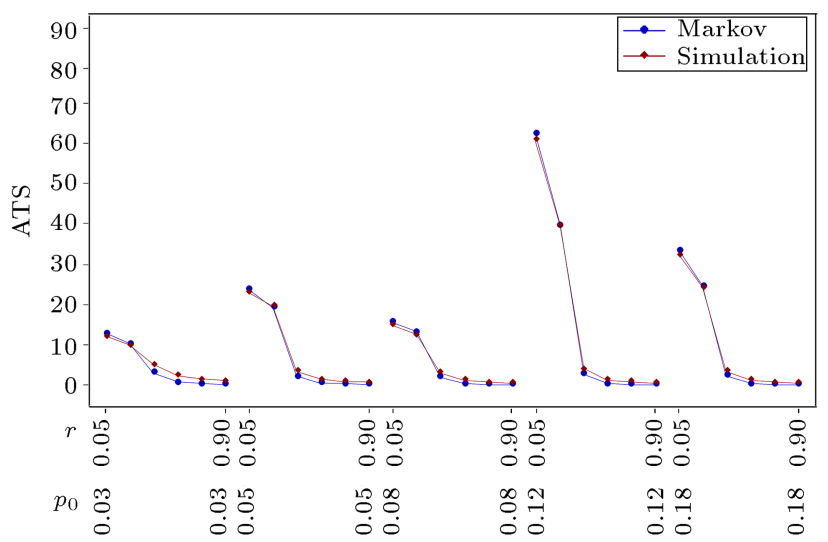

Figure 3. Comparing the optimal results of ATS obtained by Markov and simulation methods for SVSSI-np control chart when $n_{0}=6$ and $h_{0}=1.5$.

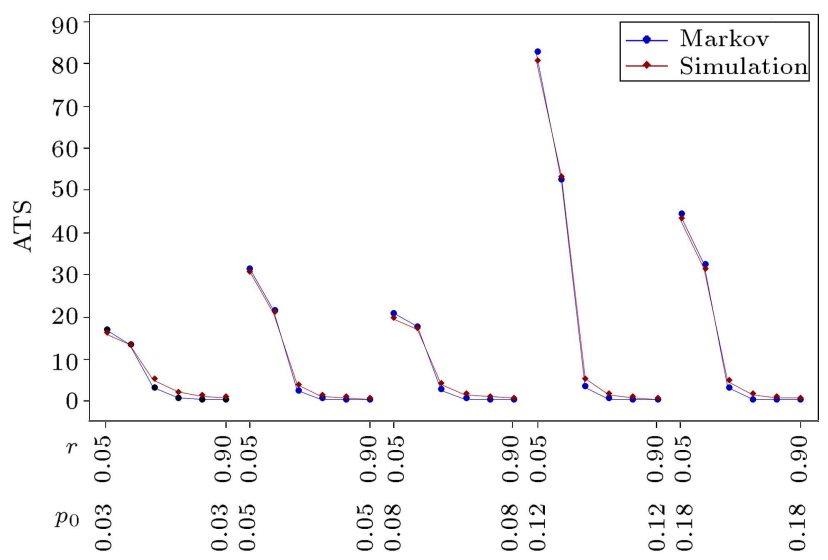

Figure 4. Comparing the optimal results of ATS obtained by Markov and simulation methods for the SVSSI-np control chart when $n_{0}=8$ and $h_{0}=2$.

distribution in 10,000 iterations. In this evaluation, the parameters are set according to Tables 7-9. As depicted in Figures 2-4, the results of simulation are almost the same as those obtained in Tables 7-9 using the Markov chain method. 
Table 2. Comparing optimal AATS values of np control charts when $n_{0}=4$ and $h_{0}=1$.

\begin{tabular}{|c|c|c|c|c|c|c|c|c|c|c|c|c|}
\hline \multirow[b]{2}{*}{$p_{0}$} & \multirow[b]{2}{*}{$\boldsymbol{r}$} & \multicolumn{5}{|c|}{ SVSSI design parameters } & \multicolumn{6}{|c|}{ AATS } \\
\hline & & $n_{1}$ & $n_{2}$ & $n_{3}$ & $h_{1}$ & $h_{2}$ & SVSSI & FA & VSSI & VSS & VSI & Shewhart \\
\hline \multirow[t]{6}{*}{0.03} & 0.05 & 3 & 9 & 10 & 1 & 0.1 & 8.5 & 8.5 & 12.69 & 12.69 & 103.17 & 117.76 \\
\hline & 0.1 & 3 & 10 & 33 & 1 & 0.2 & 6.93 & 6.93 & 10.33 & 10.34 & 67.94 & 79.71 \\
\hline & 0.3 & 3 & 47 & 48 & 1 & 0.8 & 3.83 & 3.87 & 5.88 & 5.88 & 21.35 & 27.76 \\
\hline & 0.5 & 3 & 47 & 48 & 1 & 0.9 & 2.54 & 2.59 & 3.75 & 4.06 & 9.97 & 14.2 \\
\hline & 0.7 & 3 & 47 & 48 & 1 & 0.9 & 1.91 & 1.94 & 2.36 & 3.08 & 5.65 & 8.7 \\
\hline & 0.9 & 3 & 47 & 48 & 1 & 0.9 & 1.54 & 1.56 & 1.81 & 2.46 & 3.6 & 5.91 \\
\hline \multirow[t]{6}{*}{0.05} & 0.05 & 1 & 5 & 6 & 1 & 0.2 & 15.92 & 15.92 & 55.06 & 62.7 & 48.31 & 48.32 \\
\hline & 0.1 & 1 & 6 & 48 & 1 & 0.4 & 13.42 & 13.43 & 37.85 & 43.87 & 35.15 & 35.16 \\
\hline & 0.3 & 3 & 47 & 48 & 1 & 0.1 & 4.56 & 6.86 & 8.34 & 10.71 & 14.18 & 14.18 \\
\hline & 0.5 & 3 & 47 & 48 & 1 & 0.1 & 2.18 & 2.66 & 2.85 & 3.84 & 7.73 & 7.74 \\
\hline & 0.7 & 3 & 47 & 48 & 1 & 0.1 & 1.6 & 1.68 & 1.73 & 2.46 & 4.91 & 4.92 \\
\hline & 0.9 & 3 & 47 & 48 & 1 & 0.1 & 1.3 & 1.32 & 1.35 & 2.02 & 3.41 & 3.42 \\
\hline \multirow[t]{6}{*}{0.08} & 0.05 & 1 & 4 & 8 & 1 & 0.1 & 10.19 & 10.19 & 40.06 & 40.05 & 21.14 & 21.15 \\
\hline & 0.1 & 1 & 4 & 50 & 1 & 0.1 & 8.84 & 8.84 & 30.73 & 30.72 & 16.32 & 16.34 \\
\hline & 0.3 & 3 & 49 & 50 & 1 & 0.1 & 3.35 & 5.58 & 8.33 & 11 & 7.51 & 7.52 \\
\hline & 0.5 & 3 & 49 & 50 & 1 & 0.1 & 1.58 & 2.62 & 2.71 & 3.66 & 4.36 & 4.38 \\
\hline & 0.7 & 3 & 49 & 50 & 1 & 0.1 & 1.19 & 1.75 & 1.78 & 2.43 & 2.88 & 2.89 \\
\hline & 0.9 & 3 & 49 & 50 & 1 & 0.1 & 0.99 & 1.4 & 1.42 & 2.04 & 2.05 & 2.06 \\
\hline \multirow[t]{6}{*}{0.12} & 0.05 & 2 & 5 & 8 & 1 & 0.1 & 42.24 & 53.36 & 285.66 & 297.61 & 101.36 & 109.6 \\
\hline & 0.1 & 2 & 40 & 45 & 1 & 0.1 & 27.59 & 42.47 & 176.07 & 201.8 & 71.92 & 79.1 \\
\hline & 0.3 & 3 & 45 & 50 & 1 & 0.1 & 3.17 & 11.94 & 11.94 & 14.52 & 23.99 & 28.54 \\
\hline & 0.5 & 3 & 47 & 50 & 1 & 0.1 & 1.26 & 3.78 & 3.78 & 4.61 & 10.45 & 13.58 \\
\hline & 0.7 & 3 & 47 & 50 & 1 & 0.1 & 0.96 & 2.5 & 2.5 & 3.08 & 5.32 & 7.56 \\
\hline & 0.9 & 3 & 47 & 50 & 1 & 0.1 & 0.82 & 2 & 2 & 2.58 & 3.02 & 4.66 \\
\hline \multirow[t]{6}{*}{0.18} & 0.05 & 2 & 6 & 31 & 1 & 0.1 & 22.29 & 24.7 & 128.41 & 150.23 & 620.01 & 634.49 \\
\hline & 0.1 & 2 & 49 & 50 & 1 & 0.1 & 16.62 & 20.47 & 97.47 & 115.55 & 426 & 438.88 \\
\hline & 0.3 & 2 & 49 & 50 & 1 & 0.1 & 2.78 & 9.57 & 9.57 & 12.84 & 122.49 & 131.09 \\
\hline & 0.5 & 2 & 49 & 50 & 1 & 0.1 & 1.26 & 2.68 & 2.68 & 3.59 & 45.59 & 51.67 \\
\hline & 0.7 & 2 & 49 & 50 & 1 & 0.1 & 0.98 & 1.82 & 1.82 & 2.4 & 19.7 & 24.12 \\
\hline & 0.9 & 2 & 46 & 50 & 1 & 0.1 & 0.82 & 1.42 & 1.44 & 2.04 & 9.34 & 12.59 \\
\hline
\end{tabular}

The performance of each control chart is highly dependent on the variations of sample size and sampling interval. Therefore, the proper design of the control chart is of great importance. For this reason, another assumption is considered and another method called $V S S I_{n}$ is examined. In this method, the next sampling is performed after the interval $h_{1}$ whenever the statistic is placed in the state of $W_{i}^{1} \leq n p<W_{i}^{2}$. Therefore, only $p_{2 j}$ values change as follows (other $p_{i j}$ values are calculated in the same way as SVSSI method):

$$
\begin{aligned}
& p_{21}=F\left(n_{2}, W_{2}^{1}, p_{0}\right) \times \exp \left(-\lambda h_{1}\right), \\
& p_{22}=\left(F\left(n_{2}, W_{2}^{2}, p_{0}\right)-F\left(n_{2}, W_{2}^{1}, p_{0}\right)\right) \times \exp \left(-\lambda h_{1}\right), \\
& p_{23}=\left(F\left(n_{2}, K_{2}, p_{0}\right)-F\left(n_{2}, W_{2}^{2}, p_{0}\right)\right) \times \exp \left(-\lambda h_{1}\right), \\
& p_{24}=\left(1-F\left(n_{2}, K_{2}, p_{0}\right)\right) \times \exp \left(-\lambda h_{1}\right),
\end{aligned}
$$


Table 3. Comparing optimal AATS values of np control charts when $n_{0}=6$ and $h_{0}=1.5$.

\begin{tabular}{|c|c|c|c|c|c|c|c|c|c|c|c|c|}
\hline \multirow[b]{2}{*}{$p_{0}$} & \multirow[b]{2}{*}{$\boldsymbol{r}$} & \multicolumn{5}{|c|}{ SVSSI design parameters } & \multicolumn{6}{|c|}{ AATS } \\
\hline & & $n_{1}$ & $n_{2}$ & $n_{3}$ & $h_{1}$ & $h_{2}$ & SVSSI & FA & VSSI & VSS & VSI & Shewhart \\
\hline \multirow[t]{6}{*}{0.03} & 0.05 & 3 & 9 & 10 & 1.5 & 0.1 & 12.75 & 12.75 & 19.01 & 19.02 & 73.96 & 73.97 \\
\hline & 0.1 & 3 & 10 & 33 & 1.5 & 0.2 & 10.39 & 10.4 & 15.49 & 15.49 & 50.5 & 50.52 \\
\hline & 0.3 & 3 & 47 & 48 & 1.5 & 1.2 & 5.71 & 5.79 & 8.8 & 8.8 & 18.15 & 18.17 \\
\hline & 0.5 & 5 & 47 & 48 & 1.5 & 0.1 & 2.88 & 3.26 & 3.54 & 5.08 & 9.55 & 9.56 \\
\hline & 0.7 & 5 & 47 & 48 & 1.5 & 0.1 & 2.05 & 2.14 & 2.23 & 3.37 & 6 & 6.01 \\
\hline & 0.9 & 5 & 47 & 48 & 1.5 & 0.1 & 1.66 & 1.68 & 1.73 & 2.78 & 4.17 & 4.19 \\
\hline \multirow[t]{6}{*}{0.05} & 0.05 & 1 & 6 & 20 & 1.5 & 0.3 & 23.88 & 23.88 & 44.97 & 44.97 & 31.02 & 31.04 \\
\hline & 0.1 & 1 & 6 & 48 & 1.5 & 0.5 & 20.12 & 20.14 & 32.88 & 32.88 & 22.8 & 22.82 \\
\hline & 0.3 & 5 & 48 & 49 & 1.5 & 0.1 & 4.06 & 10.2 & 12.38 & 13.49 & 9.53 & 9.55 \\
\hline & 0.5 & 5 & 48 & 49 & 1.5 & 0.1 & 2.02 & 3.95 & 4.22 & 5.7 & 5.37 & 5.39 \\
\hline & 0.7 & 5 & 48 & 49 & 1.5 & 0.1 & 1.52 & 2.49 & 2.55 & 3.64 & 3.51 & 3.53 \\
\hline & 0.9 & 5 & 48 & 49 & 1.5 & 0.1 & 1.27 & 1.95 & 1.98 & 2.98 & 2.52 & 2.54 \\
\hline \multirow[t]{6}{*}{0.08} & 0.05 & 1 & 4 & 8 & 1.5 & 0.1 & 15.29 & 15.29 & 60.06 & 60.05 & 103.61 & 113.03 \\
\hline & 0.1 & 1 & 4 & 50 & 1.5 & 0.1 & 13.26 & 13.26 & 46.06 & 46.06 & 69.56 & 77.57 \\
\hline & 0.3 & 4 & 49 & 50 & 1.5 & 0.1 & 3.67 & 8.33 & 12.34 & 16.41 & 20.71 & 25.43 \\
\hline & 0.5 & 4 & 49 & 50 & 1.5 & 0.1 & 1.81 & 3.88 & 4.01 & 5.42 & 8.75 & 11.86 \\
\hline & 0.7 & 4 & 49 & 50 & 1.5 & 0.1 & 1.39 & 2.6 & 2.63 & 3.59 & 4.52 & 6.68 \\
\hline & 0.9 & 4 & 49 & 50 & 1.5 & 0.1 & 1.17 & 2.08 & 2.1 & 3.02 & 2.7 & 4.23 \\
\hline \multirow[t]{6}{*}{0.12} & 0.05 & 2 & 5 & 8 & 1.5 & 0.1 & 62.81 & 72.76 & 139.17 & 149.78 & 353.44 & 364.56 \\
\hline & 0.1 & 2 & 40 & 45 & 1.5 & 0.1 & 40.84 & 53.09 & 97.59 & 106.55 & 229.29 & 238.93 \\
\hline & 0.3 & 3 & 45 & 50 & 1.5 & 0.1 & 4.6 & 14.41 & 17.76 & 21.64 & 58.62 & 64.65 \\
\hline & 0.5 & 3 & 47 & 50 & 1.5 & 0.1 & 1.84 & 4.7 & 4.95 & 6.38 & 21.32 & 25.38 \\
\hline & 0.7 & 3 & 47 & 50 & 1.5 & 0.1 & 1.4 & 2.82 & 2.87 & 3.94 & 9.49 & 12.34 \\
\hline & 0.9 & 3 & 47 & 50 & 1.5 & 0.1 & 1.2 & 2.05 & 2.09 & 3.15 & 4.85 & 6.88 \\
\hline \multirow[t]{6}{*}{0.18} & 0.05 & 2 & 6 & 31 & 1.5 & 0.1 & 33.04 & 37.06 & 191.41 & 208.87 & 82.17 & 88.98 \\
\hline & 0.1 & 2 & 49 & 50 & 1.5 & 0.1 & 24.51 & 30.7 & 135.77 & 144.52 & 57.67 & 63.65 \\
\hline & 0.3 & 2 & 49 & 50 & 1.5 & 0.1 & 4.04 & 14.16 & 14.16 & 19.17 & 17.94 & 21.73 \\
\hline & 0.5 & 2 & 49 & 50 & 1.5 & 0.1 & 1.85 & 3.97 & 3.97 & 5.32 & 7.25 & 9.76 \\
\hline & 0.7 & 5 & 49 & 50 & 1.5 & 0.1 & 1.34 & 2.69 & 2.69 & 3.54 & 3.5 & 5.18 \\
\hline & 0.9 & 5 & 49 & 50 & 1.5 & 0.1 & 1.09 & 2.04 & 2.08 & 3.02 & 1.96 & 3.07 \\
\hline
\end{tabular}

$$
\begin{aligned}
p_{25} & =F\left(n_{2}, W_{2}^{1}, p_{1}\right) \times\left(1-\exp \left(-\lambda h_{1}\right)\right), \\
p_{26} & =\left(F\left(n_{2}, W_{2}^{2}, p_{1}\right)-F\left(n_{2}, W_{2}^{1}, p_{1}\right)\right) \\
& \times\left(1-\exp \left(-\lambda h_{1}\right)\right), \\
p_{27} & =\left(F\left(n_{2}, K_{2}, p_{1}\right)-F\left(n_{2}, W_{2}^{2}, p_{1}\right)\right) \\
& \times\left(1-\exp \left(-\lambda h_{1}\right)\right), \\
p_{28} & =\left(1-F\left(n_{2}, K_{2}, p_{1}\right)\right) \times\left(1-\exp \left(-\lambda h_{1}\right)\right) .
\end{aligned}
$$

Besides, the AATS and ATS values are equal to:

$$
\begin{aligned}
A A T S & =B \times(I-Q)^{-1} \times\left(h_{1}, h_{1}, h_{2}, h_{2}, h_{1}, h_{1}, h_{2}\right)^{\prime} \\
& -\frac{1}{\lambda}, \\
A T S & =B^{d} \times\left(I^{d}-Q^{d}\right)^{-1} \times\left(h_{1}, h_{1}, h_{2}\right)^{\prime} .
\end{aligned}
$$

Similar to the previous investigations, the $V S S I_{n}$ sampling method is evaluated based on AATS and ATS. The results of comparing this method with the SVSSI sampling method are presented in Tables 8-10.

In each table, the values of AATS and ATS metrics for $V S S I_{n}$ and $S V S S I$ sampling methods are 
Table 4. Comparing optimal AATS values of np control charts when $n_{0}=8$ and $h_{0}=2$.

\begin{tabular}{|c|c|c|c|c|c|c|c|c|c|c|c|c|}
\hline \multirow[b]{2}{*}{$p_{0}$} & \multirow[b]{2}{*}{$\boldsymbol{r}$} & \multicolumn{5}{|c|}{ SVSSI design parameters } & \multicolumn{6}{|c|}{ AATS } \\
\hline & & $n_{1}$ & $n_{2}$ & $n_{3}$ & $h_{1}$ & $h_{2}$ & SVSSI & FA & VSSI & VSS & VSI & Shewhart \\
\hline \multirow[t]{6}{*}{0.03} & 0.05 & 3 & 9 & 10 & 2 & 0.1 & 17 & 17 & 25.34 & 25.34 & 55.16 & 55.19 \\
\hline & 0.1 & 3 & 10 & 33 & 2 & 0.3 & 13.86 & 13.87 & 20.64 & 20.64 & 37.96 & 37.99 \\
\hline & 0.3 & 7 & 47 & 48 & 2 & 0.1 & 5.81 & 7.69 & 11.72 & 11.72 & 14.03 & 14.06 \\
\hline & 0.5 & 7 & 48 & 50 & 2 & 0.1 & 2.81 & 4.32 & 4.68 & 6.69 & 7.55 & 7.59 \\
\hline & 0.7 & 7 & 48 & 50 & 2 & 0.1 & 2.04 & 2.83 & 2.94 & 4.44 & 4.85 & 4.88 \\
\hline & 0.9 & 7 & 48 & 50 & 2 & 0.1 & 1.68 & 2.22 & 2.28 & 3.65 & 3.46 & 3.49 \\
\hline \multirow[t]{6}{*}{0.05} & 0.05 & 1 & 6 & 20 & 2 & 0.4 & 31.84 & 31.85 & 59.94 & 59.94 & 184.99 & 198.49 \\
\hline & 0.1 & 6 & 48 & 49 & 2 & 0.1 & 21.91 & 26.85 & 43.82 & 43.83 & 114.87 & 126.02 \\
\hline & 0.3 & 6 & 48 & 49 & 2 & 0.1 & 4.46 & 12.4 & 16.42 & 17.98 & 29.17 & 35.35 \\
\hline & 0.5 & 7 & 47 & 48 & 2 & 0.1 & 2.12 & 5.24 & 5.59 & 7.51 & 11.63 & 15.58 \\
\hline & 0.7 & 7 & 47 & 48 & 2 & 0.1 & 1.61 & 3.3 & 3.38 & 4.78 & 5.9 & 8.6 \\
\hline & 0.9 & 7 & 47 & 48 & 2 & 0.1 & 1.38 & 2.58 & 2.62 & 3.91 & 3.52 & 5.43 \\
\hline \multirow[t]{6}{*}{0.08} & 0.05 & 1 & 4 & 12 & 2 & 0.1 & 20.39 & 20.39 & 79.2 & 80.04 & 61.48 & 61.51 \\
\hline & 0.1 & 1 & 4 & 50 & 2 & 0.2 & 17.68 & 17.69 & 53.27 & 60.15 & 42.92 & 42.95 \\
\hline & 0.3 & 4 & 49 & 50 & 2 & 0.1 & 4.83 & 10.39 & 15.37 & 19.9 & 14.97 & 15 \\
\hline & 0.5 & 4 & 49 & 50 & 2 & 0.1 & 2.39 & 3.85 & 4.25 & 6.4 & 7.37 & 7.4 \\
\hline & 0.7 & 4 & 49 & 50 & 2 & 0.1 & 1.84 & 2.41 & 2.5 & 4.04 & 4.37 & 4.4 \\
\hline & 0.9 & 4 & 49 & 50 & 2 & 0.1 & 1.56 & 1.83 & 1.89 & 3.34 & 2.91 & 2.95 \\
\hline \multirow[t]{6}{*}{0.12} & 0.05 & 2 & 5 & 40 & 2 & 0.1 & 83.38 & 97.01 & 185.31 & 199.66 & 121.58 & 130.07 \\
\hline & 0.1 & 2 & 40 & 45 & 2 & 0.1 & 54.09 & 70.77 & 129.91 & 142.03 & 80.18 & 87.48 \\
\hline & 0.3 & 3 & 45 & 50 & 2 & 0.1 & 6.03 & 19.15 & 23.58 & 28.69 & 21.77 & 26.14 \\
\hline & 0.5 & 7 & 47 & 50 & 2 & 0.1 & 2.39 & 6.18 & 6.56 & 8.39 & 8.45 & 11.25 \\
\hline & 0.7 & 7 & 47 & 50 & 2 & 0.1 & 1.7 & 3.43 & 3.51 & 5.01 & 4.12 & 5.96 \\
\hline & 0.9 & 7 & 40 & 47 & 2 & 0.1 & 1.39 & 2.35 & 2.4 & 3.9 & 2.4 & 3.61 \\
\hline \multirow[t]{6}{*}{0.18} & 0.05 & 2 & 6 & 31 & 2 & 0.1 & 43.8 & 49.42 & 254.4 & 278.43 & 186.16 & 194.59 \\
\hline & 0.1 & 2 & 49 & 50 & 2 & 0.1 & 32.39 & 40.94 & 180.82 & 192.63 & 122.33 & 129.72 \\
\hline & 0.3 & 2 & 49 & 50 & 2 & 0.1 & 5.3 & 14.61 & 18.76 & 25.45 & 31.22 & 35.81 \\
\hline & 0.5 & 2 & 49 & 50 & 2 & 0.1 & 2.45 & 4.54 & 4.89 & 7 & 11.02 & 14 \\
\hline & 0.7 & 5 & 49 & 50 & 2 & 0.1 & 1.77 & 2.67 & 2.73 & 4.22 & 4.82 & 6.76 \\
\hline & 0.9 & 5 & 46 & 50 & 2 & 0.1 & 1.44 & 1.89 & 1.95 & 3.42 & 2.54 & 3.77 \\
\hline
\end{tabular}

compared. Moreover, the percentage difference between the optimal values of each criterion is calculated. It is clear that a small change in the sampling method leads to weaker results and attenuated performance of the $n p$ control chart in most cases. Therefore, choosing the correct sampling interval and sample size in each state of the process is very important to achieve better results.

\section{Concluding remarks and future research}

By introducing variable sampling methods, a significant improvement in the performance of control charts has been achieved in terms of faster identification of shifts in the processes. After reviewing Variable Sample Size (VSS), Variable Sampling Interval (VSI), Variable Sample Size and Sampling Interval (VSSI), and Full 
Table 5. Comparing optimal ATS values of np control charts when $n_{0}=4$ and $h_{0}=1$.

\begin{tabular}{|c|c|c|c|c|c|c|c|c|c|c|c|c|}
\hline \multirow[b]{2}{*}{$p_{0}$} & \multirow[b]{2}{*}{$\boldsymbol{r}$} & \multicolumn{5}{|c|}{ SVSSI design parameters } & \multicolumn{6}{|c|}{ AATS } \\
\hline & & $n_{1}$ & $n_{2}$ & $n_{3}$ & $h_{1}$ & $h_{2}$ & SVSSI & FA & VSSI & VSS & VSI & Shewhart \\
\hline \multirow[t]{6}{*}{0.03} & 0.05 & 3 & 9 & 10 & 1 & 0.1 & 8.5 & 8.6 & 11.86 & 12.76 & 102.78 & 118.26 \\
\hline & 0.1 & 3 & 10 & 33 & 1 & 0.1 & 6.75 & 6.92 & 9.52 & 10.42 & 67.55 & 80.2 \\
\hline & 0.3 & 3 & 47 & 48 & 1 & 0.1 & 2.01 & 2.62 & 5.08 & 5.98 & 20.95 & 28.26 \\
\hline & 0.5 & 3 & 47 & 48 & 1 & 0.1 & 0.47 & 0.82 & 1.04 & 2.4 & 9.58 & 14.7 \\
\hline & 0.7 & 3 & 47 & 48 & 1 & 0.1 & 0.17 & 0.27 & 0.29 & 1.33 & 5.25 & 9.2 \\
\hline & 0.9 & 3 & 47 & 48 & 1 & 0.1 & 0.11 & 0.14 & 0.14 & 1.08 & 3.2 & 6.41 \\
\hline \multirow[t]{6}{*}{0.05} & 0.05 & 1 & 5 & 6 & 1 & 0.1 & 15.59 & 15.75 & 53.07 & 61.53 & 47.92 & 48.82 \\
\hline & 0.1 & 1 & 6 & 48 & 1 & 0.1 & 12.83 & 13.14 & 36.04 & 42.83 & 34.76 & 35.66 \\
\hline & 0.3 & 3 & 47 & 48 & 1 & 0.1 & 2.12 & 4.72 & 5.64 & 8.5 & 13.78 & 14.68 \\
\hline & 0.5 & 3 & 47 & 48 & 1 & 0.1 & 0.31 & 0.87 & 0.92 & 2.28 & 7.34 & 8.24 \\
\hline & 0.7 & 3 & 47 & 48 & 1 & 0.1 & 0.13 & 0.23 & 0.23 & 1.27 & 4.22 & 5.41 \\
\hline & 0.9 & 3 & 47 & 48 & 1 & 0.1 & 0.1 & 0.12 & 0.12 & 1.05 & 3.02 & 3.92 \\
\hline \multirow[t]{6}{*}{0.08} & 0.05 & 1 & 4 & 8 & 1 & 0.1 & 10.37 & 10.29 & 38.83 & 39.73 & 20.74 & 21.64 \\
\hline & 0.1 & 1 & 4 & 50 & 1 & 0.1 & 8.84 & 8.88 & 29.52 & 30.42 & 15.93 & 16.83 \\
\hline & 0.3 & 3 & 49 & 50 & 1 & 0.1 & 1.69 & 3.89 & 5.51 & 8.72 & 7.12 & 8.02 \\
\hline & 0.5 & 3 & 49 & 50 & 1 & 0.1 & 0.23 & 0.64 & 0.65 & 2.01 & 3.97 & 4.87 \\
\hline & 0.7 & 3 & 49 & 50 & 1 & 0.1 & 0.12 & 0.16 & 0.17 & 1.16 & 2.84 & 3.38 \\
\hline & 0.9 & 3 & 49 & 50 & 1 & 0.1 & 0.1 & 0.11 & 0.11 & 1.02 & 1.66 & 2.56 \\
\hline \multirow[t]{6}{*}{0.12} & 0.05 & 2 & 5 & 40 & 1 & 0.1 & 41.94 & 52.87 & 280.47 & 293.45 & 100.96 & 110.09 \\
\hline & 0.1 & 2 & 40 & 45 & 1 & 0.1 & 26.8 & 41.49 & 170.11 & 196.73 & 71.52 & 79.6 \\
\hline & 0.3 & 3 & 45 & 50 & 1 & 0.1 & 1.81 & 7.91 & 7.91 & 11.11 & 23.6 & 29.04 \\
\hline & 0.5 & 3 & 47 & 50 & 1 & 0.1 & 0.22 & 0.79 & 0.79 & 2.1 & 10.05 & 14.07 \\
\hline & 0.7 & 3 & 49 & 50 & 1 & 0.1 & 0.11 & 0.16 & 0.16 & 1.13 & 4.92 & 8.06 \\
\hline & 0.9 & 3 & 49 & 50 & 1 & 0.1 & 0.1 & 0.1 & 0.1 & 1.01 & 2.62 & 5.16 \\
\hline \multirow[t]{6}{*}{0.18} & 0.05 & 2 & 6 & 31 & 1 & 0.1 & 22.52 & 24.85 & 123.99 & 146.67 & 619.61 & 634.98 \\
\hline & 0.1 & 2 & 45 & 49 & 1 & 0.1 & 16.7 & 20.46 & 93.49 & 112.35 & 425.6 & 439.38 \\
\hline & 0.3 & 2 & 45 & 49 & 1 & 0.1 & 1.65 & 6.74 & 6.74 & 10.6 & 122.09 & 131.58 \\
\hline & 0.5 & 2 & 45 & 49 & 1 & 0.1 & 0.2 & 0.54 & 0.54 & 1.92 & 45.19 & 52.17 \\
\hline & 0.7 & 2 & 48 & 49 & 1 & 0.1 & 0.11 & 0.13 & 0.13 & 1.09 & 19.3 & 24.62 \\
\hline & 0.9 & 2 & 48 & 49 & 1 & 0.1 & 0.1 & 0.1 & 0.1 & 1.01 & 8.94 & 13.09 \\
\hline
\end{tabular}

Adaptive (FA) sampling methods, this study proposed a new SVSSI sampling method for the $n p$ control chart in which three sample sizes and two sampling intervals are used to design. After introduction, designing of this method based on the concept of the Markov chain was considered. To evaluate the SVSSI method and compare it to other sampling methods, the minimum Adjusted Average Time to Signal (minAATS) and the minimum Average Time to Signal (minATS) were considered as criteria. Moreover, comparisons were 
Table 6. Comparing optimal ATS values of np control charts when $n_{0}=6$ and $h_{0}=1.5$.

\begin{tabular}{|c|c|c|c|c|c|c|c|c|c|c|c|c|}
\hline \multirow[b]{2}{*}{$p_{0}$} & \multirow[b]{2}{*}{$\boldsymbol{r}$} & \multicolumn{5}{|c|}{ SVSSI design parameters } & \multicolumn{6}{|c|}{ AATS } \\
\hline & & $n_{1}$ & $n_{2}$ & $n_{3}$ & $h_{1}$ & $h_{2}$ & SVSSI & FA & VSSI & VSS & VSI & Shewhart \\
\hline \multirow[t]{6}{*}{0.03} & 0.05 & 3 & 9 & 10 & 1.5 & 0.1 & 12.67 & 12.86 & 17.74 & 19.14 & 73.31 & 74.71 \\
\hline & 0.1 & 3 & 10 & 33 & 1.5 & 0.1 & 10.05 & 10.32 & 14.22 & 15.62 & 49.86 & 51.26 \\
\hline & 0.3 & 3 & 47 & 48 & 1.5 & 0.1 & 2.93 & 3.87 & 5.83 & 8.97 & 17.51 & 18.91 \\
\hline & 0.5 & 5 & 47 & 48 & 1.5 & 0.1 & 0.51 & 0.98 & 1.05 & 3.16 & 8.9 & 10.3 \\
\hline & 0.7 & 5 & 47 & 48 & 1.5 & 0.1 & 0.17 & 0.29 & 0.29 & 1.92 & 5.35 & 6.75 \\
\hline & 0.9 & 5 & 47 & 48 & 1.5 & 0.1 & 0.11 & 0.14 & 0.14 & 1.61 & 3.53 & 4.93 \\
\hline \multirow[t]{6}{*}{0.05} & 0.05 & 1 & 6 & 20 & 1.5 & 0.1 & 23.56 & 23.57 & 43.71 & 45.11 & 30.38 & 31.78 \\
\hline & 0.1 & 1 & 6 & 48 & 1.5 & 0.1 & 19.16 & 19.66 & 31.64 & 33.04 & 22.16 & 23.56 \\
\hline & 0.3 & 5 & 47 & 48 & 1.5 & 0.1 & 2.04 & 6.94 & 8.31 & 12.75 & 8.89 & 10.29 \\
\hline & 0.5 & 5 & 47 & 48 & 1.5 & 0.1 & 0.31 & 1.23 & 1.3 & 3.42 & 4.73 & 6.13 \\
\hline & 0.7 & 5 & 47 & 48 & 1.5 & 0.1 & 0.13 & 0.28 & 0.28 & 1.9 & 2.87 & 4.28 \\
\hline & 0.9 & 5 & 47 & 48 & 1.5 & 0.1 & 0.11 & 0.13 & 0.13 & 1.58 & 1.88 & 3.28 \\
\hline \multirow[t]{6}{*}{0.08} & 0.05 & 1 & 4 & 8 & 1.5 & 0.1 & 15.5 & 15.39 & 58.2 & 59.6 & 102.96 & 113.77 \\
\hline & 0.1 & 1 & 4 & 50 & 1.5 & 0.1 & 13.17 & 13.27 & 44.23 & 45.63 & 68.91 & 78.31 \\
\hline & 0.3 & 4 & 49 & 50 & 1.5 & 0.1 & 1.9 & 5.76 & 8.09 & 13.08 & 20.05 & 26.17 \\
\hline & 0.5 & 4 & 49 & 50 & 1.5 & 0.1 & 0.25 & 0.88 & 0.9 & 3.02 & 8.1 & 12.6 \\
\hline & 0.7 & 4 & 49 & 50 & 1.5 & 0.1 & 0.12 & 0.19 & 0.19 & 1.74 & 3.87 & 7.42 \\
\hline & 0.9 & 4 & 49 & 50 & 1.5 & 0.1 & 0.1 & 0.11 & 0.11 & 1.53 & 2.05 & 4.97 \\
\hline \multirow[t]{6}{*}{0.12} & 0.05 & 2 & 5 & 40 & 1.5 & 0.1 & 62.3 & 72.27 & 137.18 & 149.15 & 352.79 & 365.3 \\
\hline & 0.1 & 2 & 40 & 45 & 1.5 & 0.1 & 39.6 & 51.95 & 95.71 & 106 & 228.62 & 239.68 \\
\hline & 0.3 & 3 & 45 & 50 & 1.5 & 0.1 & 2.54 & 9.58 & 11.68 & 16.66 & 57.97 & 65.39 \\
\hline & 0.5 & 3 & 47 & 50 & 1.5 & 0.1 & 0.26 & 0.97 & 1.01 & 3.04 & 20.66 & 26.12 \\
\hline & 0.7 & 3 & 49 & 50 & 1.5 & 0.1 & 0.11 & 0.17 & 0.17 & 1.68 & 8.83 & 13.08 \\
\hline & 0.9 & 3 & 49 & 50 & 1.5 & 0.1 & 0.1 & 0.1 & 0.1 & 1.52 & 4.19 & 7.62 \\
\hline \multirow[t]{6}{*}{0.18} & 0.05 & 2 & 6 & 31 & 1.5 & 0.1 & 33.34 & 37.22 & 184.73 & 207.68 & 81.52 & 88.72 \\
\hline & 0.1 & 2 & 45 & 49 & 1.5 & 0.1 & 24.54 & 30.64 & 133.12 & 143.4 & 57.01 & 64.39 \\
\hline & 0.3 & 2 & 45 & 49 & 1.5 & 0.1 & 2.3 & 9.9 & 9.9 & 15.89 & 17.29 & 22.47 \\
\hline & 0.5 & 5 & 45 & 49 & 1.5 & 0.1 & 0.22 & 0.74 & 0.74 & 2.88 & 6.6 & 10.5 \\
\hline & 0.7 & 5 & 48 & 49 & 1.5 & 0.1 & 0.11 & 0.14 & 0.14 & 1.64 & 2.84 & 5.92 \\
\hline & 0.9 & 5 & 48 & 49 & 1.5 & 0.1 & 0.1 & 0.1 & 0.1 & 1.51 & 1.31 & 3.81 \\
\hline
\end{tabular}

made based on different values of $p_{0}, d, n_{0}$, and $h_{0}$ to evaluate the sampling methods from different angles. Optimal values of the criteria and parameters of the control chart were obtained through grid search and exact method.

The results of different numerical comparisons indicate the superiority of SVSSI sampling method. Besides, by making a change in the design of the method, $V S S I_{n}$ method was introduced. The results of $V S S I_{n}$ comparison proved the superiority of SVSSI again. Therefore, by choosing the proper sampling method and parameters, the duration of the out- 
Table 7. Comparing optimal ATS values of $\mathrm{np}$ control charts when $n_{0}=8$ and $h_{0}=2$.

\begin{tabular}{|c|c|c|c|c|c|c|c|c|c|c|c|c|}
\hline \multirow[b]{2}{*}{$p_{0}$} & \multirow[b]{2}{*}{$\boldsymbol{r}$} & \multicolumn{5}{|c|}{ SVSSI design parameters } & \multicolumn{6}{|c|}{ AATS } \\
\hline & & $n_{1}$ & $n_{2}$ & $n_{3}$ & $h_{1}$ & $h_{2}$ & SVSSI & FA & VSSI & VSS & VSI & Shewhart \\
\hline \multirow[t]{6}{*}{0.03} & 0.05 & 3 & 9 & 10 & 2 & 0.1 & 16.85 & 17.11 & 23.62 & 25.52 & 54.27 & 56.17 \\
\hline & 0.1 & 3 & 10 & 33 & 2 & 0.1 & 13.35 & 13.72 & 18.93 & 20.83 & 37.08 & 38.98 \\
\hline & 0.3 & 7 & 47 & 48 & 2 & 0.1 & 3 & 5.12 & 7.68 & 11.96 & 13.14 & 15.04 \\
\hline & 0.5 & 7 & 47 & 48 & 2 & 0.1 & 0.53 & 1.26 & 1.34 & 4.21 & 6.67 & 8.57 \\
\hline & 0.7 & 7 & 47 & 48 & 2 & 0.1 & 0.18 & 0.34 & 0.35 & 2.56 & 3.97 & 5.87 \\
\hline & 0.9 & 7 & 47 & 48 & 2 & 0.1 & 0.12 & 0.15 & 0.15 & 2.15 & 2.57 & 4.47 \\
\hline \multirow[t]{6}{*}{0.05} & 0.05 & 1 & 6 & 20 & 2 & 0.1 & 31.36 & 31.39 & 58.25 & 60.15 & 184.08 & 199.48 \\
\hline & 0.1 & 6 & 20 & 48 & 2 & 0.1 & 21.36 & 26.18 & 42.15 & 44.05 & 113.97 & 127 \\
\hline & 0.3 & 7 & 47 & 48 & 2 & 0.1 & 2.28 & 8.64 & 10.97 & 17 & 28.27 & 36.33 \\
\hline & 0.5 & 7 & 47 & 48 & 2 & 0.1 & 0.33 & 1.6 & 1.68 & 4.57 & 10.72 & 16.56 \\
\hline & 0.7 & 7 & 47 & 48 & 2 & 0.1 & 0.13 & 0.33 & 0.34 & 2.54 & 4.99 & 9.58 \\
\hline & 0.9 & 7 & 47 & 48 & 2 & 0.1 & 0.11 & 0.14 & 0.14 & 2.11 & 2.62 & 6.41 \\
\hline \multirow[t]{6}{*}{0.08} & 0.05 & 1 & 4 & 12 & 2 & 0.1 & 20.72 & 24.49 & 77.57 & 79.47 & 60.59 & 62.49 \\
\hline & 0.1 & 1 & 4 & 50 & 2 & 0.1 & 17.51 & 17.66 & 51.9 & 60.49 & 42.03 & 43.93 \\
\hline & 0.3 & 4 & 49 & 50 & 2 & 0.1 & 2.43 & 7.04 & 10.06 & 16.83 & 14.09 & 15.99 \\
\hline & 0.5 & 4 & 49 & 50 & 2 & 0.1 & 0.29 & 0.91 & 0.98 & 3.85 & 6.49 & 8.39 \\
\hline & 0.7 & 4 & 49 & 50 & 2 & 0.1 & 0.12 & 0.19 & 0.19 & 2.3 & 3.48 & 5.38 \\
\hline & 0.9 & 4 & 49 & 50 & 2 & 0.1 & 0.1 & 0.11 & 0.11 & 2.04 & 2.03 & 3.93 \\
\hline \multirow[t]{6}{*}{0.12} & 0.05 & 2 & 5 & 40 & 2 & 0.1 & 82.66 & 96.32 & 182.62 & 198.87 & 120.67 & 131.05 \\
\hline & 0.1 & 2 & 40 & 45 & 2 & 0.1 & 52.4 & 69.22 & 127.37 & 141.33 & 79.27 & 88.47 \\
\hline & 0.3 & 3 & 45 & 50 & 2 & 0.1 & 3.27 & 12.68 & 15.46 & 22.21 & 20.87 & 27.12 \\
\hline & 0.5 & 7 & 47 & 50 & 2 & 0.1 & 0.3 & 1.23 & 1.29 & 4.05 & 7.54 & 12.23 \\
\hline & 0.7 & 7 & 49 & 50 & 2 & 0.1 & 0.12 & 0.19 & 0.19 & 2.23 & 3.21 & 6.94 \\
\hline & 0.9 & 7 & 49 & 50 & 2 & 0.1 & 0.1 & 0.11 & 0.11 & 2.02 & 1.5 & 4.6 \\
\hline \multirow[t]{6}{*}{0.18} & 0.05 & 2 & 6 & 31 & 2 & 0.1 & 44.15 & 49.59 & 245.47 & 276.91 & 185.25 & 195.58 \\
\hline & 0.1 & 2 & 45 & 49 & 2 & 0.1 & 32.39 & 40.82 & 177.24 & 191.21 & 121.42 & 130.7 \\
\hline & 0.3 & 2 & 45 & 49 & 2 & 0.1 & 2.95 & 10.32 & 13.05 & 21.19 & 30.31 & 36.79 \\
\hline & 0.5 & 5 & 49 & 50 & 2 & 0.1 & 0.24 & 0.84 & 0.88 & 3.79 & 10.11 & 14.98 \\
\hline & 0.7 & 5 & 48 & 49 & 2 & 0.1 & 0.11 & 0.14 & 0.14 & 2.17 & 3.91 & 7.74 \\
\hline & 0.9 & 5 & 48 & 49 & 2 & 0.1 & 0.1 & 0.1 & 0.1 & 2.01 & 1.63 & 4.75 \\
\hline
\end{tabular}

of-control state was reduced and the changes that occurred in the process mean could be detected quickly. As a result, generating more defective items than those from other methods can be avoided. Thus, from a theoretical point of view and taking into account practical considerations, it can be admitted that the application of three sample sizes and two sampling intervals, as shown in Figure 1, is a superior and more efficient method than other in detecting the changes.

The $n p$ control chart is used to decide whether the observations match the technical specifications and prespecified requirements or not. Thus, several qualitative 
Table 8. Comparing optimal AATS and ATS values of sampling methods $V S S I_{n}$ and SVSSI when $n_{0}=4$ and $h_{0}=1$.

\begin{tabular}{|c|c|c|c|c|c|c|c|}
\hline \multirow[b]{2}{*}{$p_{0}$} & \multirow[b]{2}{*}{$r$} & \multicolumn{3}{|c|}{ AATS } & \multicolumn{3}{|c|}{ ATS } \\
\hline & & $\mathrm{VSSI}_{n}$ & SVSSI & $\Delta_{A A T S}(\%)$ & $\mathrm{VSSI}_{n}$ & SVSSI & $\Delta_{A T S}(\%)$ \\
\hline \multirow[t]{6}{*}{0.03} & 0.05 & 8.5013 & 8.4971 & 0.05 & 8.7896 & 8.4952 & 3.35 \\
\hline & 0.1 & 6.9334 & 6.9272 & 0.09 & 7.0473 & 6.754 & 4.16 \\
\hline & 0.3 & 3.8312 & 3.8266 & 0.12 & 2.3251 & 2.0114 & 13.49 \\
\hline & 0.5 & 2.5413 & 2.5409 & 0.02 & 0.5978 & 0.4659 & 22.06 \\
\hline & 0.7 & 1.911 & 1.9117 & -0.04 & 0.2096 & 0.1689 & 19.42 \\
\hline & 0.9 & 1.5413 & 1.542 & -0.05 & 0.1243 & 0.1137 & 8.53 \\
\hline \multirow[t]{6}{*}{0.05} & 0.05 & 15.9262 & 15.919 & 0.05 & 15.9077 & 15.5929 & 1.98 \\
\hline & 0.1 & 13.4314 & 13.4159 & 0.12 & 13.2502 & 12.8262 & 3.2 \\
\hline & 0.3 & 5.3062 & 4.557 & 14.12 & 3.0394 & 2.1169 & 30.35 \\
\hline & 0.5 & 2.32 & 2.1823 & 5.94 & 0.5317 & 0.3076 & 42.15 \\
\hline & 0.7 & 1.6022 & 1.5982 & 0.25 & 0.1815 & 0.13 & 28.37 \\
\hline & 0.9 & 1.2799 & 1.3006 & -1.62 & 0.1152 & 0.1049 & 8.94 \\
\hline \multirow[t]{6}{*}{0.08} & 0.05 & 10.1952 & 10.1935 & 0.02 & 10.4754 & 10.3715 & 0.99 \\
\hline & 0.1 & 8.8402 & 8.8374 & 0.03 & 8.9986 & 8.8367 & 1.8 \\
\hline & 0.3 & 4.847 & 3.3472 & 30.94 & 2.923 & 1.6902 & 42.18 \\
\hline & 0.5 & 2.1268 & 1.5804 & 25.69 & 0.3978 & 0.2322 & 41.63 \\
\hline & 0.7 & 1.599 & 1.1882 & 25.69 & 0.1379 & 0.1162 & 15.74 \\
\hline & 0.9 & 1.3343 & 0.9856 & 26.13 & 0.1044 & 0.1021 & 2.2 \\
\hline \multirow[t]{6}{*}{0.12} & 0.05 & 52.2464 & 42.2385 & 19.16 & 51.8923 & 41.9391 & 19.18 \\
\hline & 0.1 & 36.4141 & 27.5882 & 24.24 & 35.5929 & 26.8033 & 24.69 \\
\hline & 0.3 & 4.8657 & 3.1654 & 34.94 & 3.1696 & 1.8134 & 42.79 \\
\hline & 0.5 & 1.7806 & 1.2646 & 28.98 & 0.3785 & 0.2238 & 40.87 \\
\hline & 0.7 & 1.3086 & 0.9575 & 26.83 & 0.1278 & 0.1118 & 12.52 \\
\hline & 0.9 & 1.1198 & 0.8173 & 27.01 & 0.1021 & 0.101 & 1.08 \\
\hline \multirow[t]{6}{*}{0.18} & 0.05 & 28.8104 & 22.2859 & 22.65 & 29.0045 & 22.521 & 22.35 \\
\hline & 0.1 & 23.4137 & 16.6226 & 29 & 23.3607 & 16.6961 & 28.53 \\
\hline & 0.3 & 4.5333 & 2.7774 & 38.73 & 3.1359 & 1.6543 & 47.25 \\
\hline & 0.5 & 1.7627 & 1.2556 & 28.77 & 0.3427 & 0.195 & 43.1 \\
\hline & 0.7 & 1.3426 & 0.976 & 27.31 & 0.1177 & 0.1074 & 8.75 \\
\hline & 0.9 & 1.1494 & 0.8241 & 28.3 & 0.1009 & 0.1004 & 0.5 \\
\hline
\end{tabular}

characteristics can be examined simultaneously in this control chart. Based on such features, the chart control $n p$ is widely applied in practice. This chart is a useful tool to control and evaluate the behavior of a process from low-cost operations to mass production over time.
Thus, practitioners can identify and stop problems before experiencing great losses. The main purpose of this paper was to investigate this issue by evaluating AATS and ATS criteria for different sampling schemes in order to present the best design in terms of reducing 
Table 9. Comparing optimal AATS and ATS values of sampling methods $V S S I_{n}$ and $S V S S I$ when $n_{0}=6$ and $h_{0}=1.5$.

\begin{tabular}{|c|c|c|c|c|c|c|c|}
\hline \multirow[b]{2}{*}{$p_{0}$} & \multirow[b]{2}{*}{$r$} & \multicolumn{3}{|c|}{ AATS } & \multicolumn{3}{|c|}{ ATS } \\
\hline & & $\mathrm{VSSI}_{n}$ & SVSSI & $\Delta_{A A T S}(\%)$ & $\mathrm{VSSI}_{n}$ & SVSSI & $\Delta_{A T S}(\%)$ \\
\hline \multirow[t]{6}{*}{0.03} & 0.05 & 12.7536 & 12.7483 & 0.04 & 13.1341 & 12.6747 & 3.5 \\
\hline & 0.1 & 10.4022 & 10.3922 & 0.1 & 10.5133 & 10.0515 & 4.39 \\
\hline & 0.3 & 5.7177 & 5.7095 & 0.14 & 3.4204 & 2.9325 & 14.26 \\
\hline & 0.5 & 3.0163 & 2.8848 & 4.36 & 0.7305 & 0.508 & 30.46 \\
\hline & 0.7 & 2.0646 & 2.0529 & 0.57 & 0.2366 & 0.1738 & 26.54 \\
\hline & 0.9 & 1.6457 & 1.6597 & -0.85 & 0.1299 & 0.1146 & 11.78 \\
\hline \multirow[t]{6}{*}{0.05} & 0.05 & 23.8918 & 23.8822 & 0.04 & 23.9837 & 23.5588 & 1.77 \\
\hline & 0.1 & 20.1496 & 20.1205 & 0.14 & 19.8199 & 19.1602 & 3.33 \\
\hline & 0.3 & 6.2904 & 4.0606 & 35.45 & 3.9829 & 2.0388 & 48.81 \\
\hline & 0.5 & 2.8966 & 2.0213 & 30.22 & 0.7203 & 0.3133 & 56.5 \\
\hline & 0.7 & 2.0862 & 1.5169 & 27.29 & 0.2183 & 0.1313 & 39.85 \\
\hline & 0.9 & 1.7101 & 1.2669 & 25.92 & 0.2108 & 0.1051 & 50.14 \\
\hline \multirow[t]{6}{*}{0.08} & 0.05 & 15.2945 & 15.2924 & 0.01 & 15.6583 & 15.4978 & 1.03 \\
\hline & 0.1 & 13.2626 & 13.2589 & 0.03 & 13.4414 & 13.1742 & 1.99 \\
\hline & 0.3 & 5.759 & 3.6676 & 36.32 & 3.6801 & 1.9008 & 48.35 \\
\hline & 0.5 & 2.5532 & 1.8064 & 29.25 & 0.5024 & 0.2513 & 49.98 \\
\hline & 0.7 & 1.8969 & 1.3874 & 26.86 & 0.1514 & 0.1177 & 22.26 \\
\hline & 0.9 & 1.5755 & 1.1742 & 25.47 & 0.1058 & 0.1022 & 3.4 \\
\hline \multirow[t]{6}{*}{0.12} & 0.05 & 73.7149 & 62.809 & 14.79 & 73.3425 & 62.2976 & 15.06 \\
\hline & 0.1 & 50.1509 & 40.8394 & 18.57 & 48.9955 & 39.5995 & 19.18 \\
\hline & 0.3 & 7.2481 & 4.5974 & 36.57 & 4.6493 & 2.5397 & 45.37 \\
\hline & 0.5 & 2.6563 & 1.8447 & 30.55 & 0.5033 & 0.2619 & 47.96 \\
\hline & 0.7 & 1.9551 & 1.4046 & 28.16 & 0.1388 & 0.1139 & 17.94 \\
\hline & 0.9 & 1.6721 & 1.198 & 28.35 & 0.1028 & 0.1011 & 1.65 \\
\hline \multirow[t]{6}{*}{0.18} & 0.05 & 43.1859 & 33.0408 & 23.49 & 43.4258 & 33.3357 & 23.24 \\
\hline & 0.1 & 35.0879 & 24.5061 & 30.16 & 34.9532 & 24.5435 & 29.78 \\
\hline & 0.3 & 6.7612 & 4.0397 & 40.25 & 4.6031 & 2.3004 & 50.02 \\
\hline & 0.5 & 2.5605 & 1.8513 & 27.7 & 0.4331 & 0.2199 & 49.23 \\
\hline & 0.7 & 1.7901 & 1.3406 & 25.11 & 0.1225 & 0.108 & 11.84 \\
\hline & 0.9 & 1.4402 & 1.0884 & 24.43 & 0.101 & 0.1004 & 0.59 \\
\hline
\end{tabular}

the time of signal. Therefore, the practitioners can use the SVSSI scheme as an efficient scheme to reduce the time of signal, leading to a reduction in the production of defective items. For this purpose, after considering the parameters of the control chart and evaluating its performance, they can decide whether to reduce or increase the sample size and sampling interval.

For future research, one can consider cases in which the distribution of the failure or the duration of in-control time is not exponential. Moreover, the 
Table 10. Comparing optimal AATS and ATS values of sampling methods $V S S I_{n}$ and $S V S S I$ when $n_{0}=8$ and $h_{0}=2$.

\begin{tabular}{|c|c|c|c|c|c|c|c|}
\hline \multirow[b]{2}{*}{$p_{0}$} & \multirow[b]{2}{*}{$r$} & \multicolumn{3}{|c|}{ AATS } & \multicolumn{3}{|c|}{ ATS } \\
\hline & & $\mathrm{VSSI}_{n}$ & SVSSI & $\Delta_{A A T S}(\%)$ & $\mathrm{VSSI}_{n}$ & SVSSI & $\Delta_{A T S}(\%)$ \\
\hline \multirow[t]{6}{*}{0.03} & 0.05 & 17.0079 & 17.0017 & 0.04 & 17.4782 & 16.8542 & 3.57 \\
\hline & 0.1 & 13.8732 & 13.8584 & 0.11 & 13.9788 & 13.3489 & 4.51 \\
\hline & 0.3 & 7.5865 & 5.8079 & 23.44 & 4.5157 & 2.9951 & 33.67 \\
\hline & 0.5 & 3.9793 & 2.8055 & 29.5 & 0.9301 & 0.5265 & 43.39 \\
\hline & 0.7 & 2.7303 & 2.0385 & 25.34 & 0.2744 & 0.1788 & 34.84 \\
\hline & 0.9 & 2.1779 & 1.6849 & 22.64 & 0.1372 & 0.1158 & 15.6 \\
\hline \multirow[t]{6}{*}{0.05} & 0.05 & 31.8596 & 31.8447 & 0.05 & 31.945 & 31.3639 & 1.82 \\
\hline & 0.1 & 26.8694 & 21.9112 & 18.45 & 26.3896 & 21.3569 & 19.07 \\
\hline & 0.3 & 7.2704 & 4.4564 & 38.7 & 4.7945 & 2.2782 & 52.48 \\
\hline & 0.5 & 3.2422 & 2.1247 & 34.47 & 0.877 & 0.3334 & 61.98 \\
\hline & 0.7 & 2.2409 & 1.6059 & 28.34 & 0.2499 & 0.134 & 46.38 \\
\hline & 0.9 & 1.8509 & 1.3823 & 25.32 & 0.1249 & 0.1055 & 15.53 \\
\hline \multirow[t]{6}{*}{0.08} & 0.05 & 20.396 & 20.3942 & 0.01 & 20.8412 & 20.7221 & 0.57 \\
\hline & 0.1 & 17.6871 & 17.682 & 0.03 & 17.8843 & 17.5118 & 2.08 \\
\hline & 0.3 & 7.6622 & 4.8259 & 37.02 & 4.8429 & 2.4282 & 49.86 \\
\hline & 0.5 & 3.4046 & 2.3904 & 29.79 & 0.6148 & 0.2851 & 53.63 \\
\hline & 0.7 & 2.3458 & 1.8421 & 21.47 & 0.1637 & 0.12 & 26.7 \\
\hline & 0.9 & 1.795 & 1.5611 & 13.03 & 0.1071 & 0.1023 & 4.48 \\
\hline \multirow[t]{6}{*}{0.12} & 0.05 & 98.2828 & 83.3819 & 15.16 & 97.746 & 82.656 & 15.44 \\
\hline & 0.1 & 66.8477 & 54.093 & 19.08 & 65.2661 & 52.3957 & 19.72 \\
\hline & 0.3 & 9.3683 & 6.0316 & 35.62 & 5.8789 & 3.2659 & 44.45 \\
\hline & 0.5 & 3.3331 & 2.3928 & 28.21 & 0.6056 & 0.2977 & 50.84 \\
\hline & 0.7 & 2.2666 & 1.7003 & 24.98 & 0.1479 & 0.1154 & 21.97 \\
\hline & 0.9 & 1.8029 & 1.3909 & 22.85 & 0.1034 & 0.1011 & 2.22 \\
\hline \multirow[t]{6}{*}{0.18} & 0.05 & 57.5619 & 43.798 & 23.91 & 57.847 & 44.1504 & 23.68 \\
\hline & 0.1 & 46.7633 & 32.392 & 30.73 & 46.5457 & 32.3909 & 30.41 \\
\hline & 0.3 & 8.9931 & 5.3045 & 41.02 & 6.0703 & 2.9465 & 51.46 \\
\hline & 0.5 & 3.3994 & 2.4492 & 27.95 & 0.5307 & 0.2447 & 53.89 \\
\hline & 0.7 & 2.3808 & 1.7697 & 25.67 & 0.1278 & 0.1086 & 15.02 \\
\hline & 0.9 & 1.8612 & 1.4368 & 22.8 & 0.1012 & 0.1004 & 0.79 \\
\hline
\end{tabular}

SVSSI-np control chart can be evaluated for further research from different economic and economicstatistical points of view (see e.g. [47]). The improvement of the $n p$ control chart by designing other sampling methods necessitates more investigations. For the time being, we are trying to extend this study for an fraction defective chart expanded in [48]. The occurrence of an assignable cause in the process was one of the main assumptions of this study. Assuming the occurrence of multiple assignable causes is another suggestion for future research to pursue.

\section{Acknowledgements}

The authors would like to thank the anonymous reviewers for their useful comments and suggestions. 


\section{References}

1. Teoh, W.L., Chong, J., Khoo, M.B., et al. "Optimal designs of the variable sample size chart based on median run length and expected median run length", Qual. Reliab. Eng. Int., 33(1), pp. 121-134 (2017).

2. Muhammad, A.N.B., Yeong, W.C., Lin, C.Z., et al. "Monitoring the coefficient of variation using a variable sample size EWMA chart", Comput. Ind. Eng., 126, pp. 378-398 (2018).

3. Annadi, H.P., Keats, J., Runger, G., et al. "An adaptive sample size CUSUM control chart", Int. J. Prod. Res., 33(6), pp. 1605-1616 (1995).

4. Amiri, A., Nedaie, A., and Alikhani, M. "A new adaptive variable sample size approach in EWMA control chart", Commun. Stat.-Simul. Comput., 43(4), pp. 804-812 (2014).

5. Aparisi, F. "Hotelling's T2 control chart with adaptive sample sizes", Int. J. Prod. Res., 34(10), pp. 28532862 (1996).

6. Yeong, W.C., Khoo, M.B.C., Lim, S.L., et al. "A direct procedure for monitoring the coefficient of variation using a variable sample size scheme", Commun. Stat.Simul. Comput., 46(6), pp. 4210-4225 (2017).

7. Khaw, K.W., Chew, X., Teh, S.Y., et al. "Optimal variable sample size and sampling interval control chart for the process mean based on expected average time to signal", Int. J. Mach. Learn. Comput., 9(6), pp. 880-885 (2019).

8. Khoo, M.B.C., See, M.Y., Chong, N.L., et al. "An improved variable sample size and sampling interval S control chart", Qual. Reliab. Eng. Int., 35(1), pp. 392-404 (2019).

9. Khatun, M., Khoo, M.B.C., Yeong, W.C., et al. "Adaptive multivariate double sampling and variable sampling interval Hotelling's T2 charts", Qual. Reliab. Eng. Int., 34(5), pp. 894-911 (2018).

10. Shojaie-Navokh, M., Fallahnezhad, M., and ZareMehrjerdi, Y. "Evaluating statistically constrained economic design for monitoring the average number of non-conformities with adaptive sampling schemes", Int. J. Qual. Eng. Technol., 7(2), pp. 164-177 (2018).

11. Costa, A.F.B. and Rahim, M.A. "Economic design of $\mathrm{X}$ charts with variable parameters: The Markov chain approach", J. Appl. Stat., 28(7), pp. 875-885 (2001).

12. Faraz, A., Heuchenne, C., Saniga, E., et al. "Doubleobjective economic statistical design of the VP T2 control chart: Wald's identity approach", J. Stat. Comput. Simul., 84(10), pp. 2123-2137 (2014).

13. Katebi, M. and Moghadam, M.B. "Optimal statistical, economic and economic statistical designs of attribute np control charts using a full adaptive approach", Commun. Stat.-Theor. M., 48(18), pp. 4528-4549 (2019).
14. Abolmohammadi, M., Seif, A., Behzadi, M.H., et al. "Economic statistical design of adaptive $\overline{\mathrm{X}}$ control charts based on quality loss functions", Operational Research, 21(2), pp. 1041-1080 (2021).

15. Salmasnia, A., Kaveie, M., and Namdar, M. "An integrated production and maintenance planning model under VP-T2 Hotelling chart", Comput. Ind. Eng., 118, pp. 89-103 (2018).

16. Seif, A., Faraz, A., and Saniga, E. "Economic statistical design of the VP control charts for monitoring a process under non-normality", Int. J. Prod. Res., 53(14), pp. 4218-4230 (2015).

17. Prabhu, S.S., Montgomery, D.C., and Runger, G.C. "A combined adaptive sample size and sampling interval $\bar{X}$ control scheme", J. Qual. Technol, 26(3), pp. 164176 (1994).

18. Aparisi, F. and Haro, C.L. "Hotelling's T2 control chart with variable sampling intervals", Int. J. Prod. Res., 39(14), pp. 3127-3140 (2001).

19. Aparisi, F. and Haro, C.L. "A comparison of T2 control charts with variable sampling schemes as opposed to MEWMA chart", Int. J. Prod. Res., 41(10), pp. 21692182 (2003).

20. Kazemzadeh, R.B., Amiri, A., and Kouhestani, B. "Monitoring simple linear profiles using variable sample size schemes", J. Stat. Comput. Simul., 86(15), pp. 2923-2945 (2016).

21. Luo, H. and Wu, Z. "Optimal np control charts with variable sample sizes or variable sampling intervals", Stochastics Qual. Control, 17(1), pp. 39-61 (2002).

22. Wu, Z. and Luo, H. "Optimal design of the adaptive sample size and sampling interval np control chart", Qual. Reliab. Eng. Int., 20(6), pp. 553-570 (2004).

23. Abdella, G.M., Yang, K., and Alaeddini, A. "Multivariate adaptive approach for monitoring simple linear profiles", Int. J. Data Anal. Tech. Strateg., 6(1), pp. 2-14 (2014).

24. Chen, Y.-K. and Hsieh, K.-L. "Hotelling's T2 charts with variable sample size and control limit", Eur. J. Oper. Res., 182(3), pp. 1251-1262 (2007).

25. Lee, M.H. and Khoo, M.B.C. "Multivariate synthetic |S| control chart with variable sampling interval", Commun. Stat.-Simul. Comput., 44(4), pp. 924-942 (2015).

26. Zhang, Y., Castagliola, P., Wu, Z., et al. "The variable sampling interval $\bar{X}$ chart with estimated parameters", Qual. Reliab. Eng. Int., 28(1), pp. 19-34 (2012).

27. Chen, Y.-K., Chen, C.-Y., and Chiou, K.-C. "Cumulative conformance count chart with variable sampling intervals and control limits", Appl. Stochastic Models Bus. Ind., 27(4), pp. 410-420 (2011). 
28. Castagliola, P., Celano, G., Fichera, S., et al. "A variable sample size S2-EWMA control chart for monitoring the process variance", Int. J. Reliab. Qual. Safe. Eng., 15(3), pp. 181-201 (2008).

29. Costa, A.F.B. " $\bar{X}$ chart with variable sample size and sampling intervals", J. Qual. Technol., 29(2), pp. 197204 (1997).

30. Faraz, A., Chalaki, K., and Moghadam, M.B. "On the properties of the hotelling's T2 control chart with variable sampling intervals", Qual. Quant., 45(3), pp. 579-586 (2011).

31. Lin, Y.-C. and Chou, C.-Y. "On the design of variable sample size and sampling intervals $\bar{X}$ charts under nonnormality", Int. J. Prod. Econ., 96(2), pp. 249-261 (2005).

32. Celano, G., Costa, A., and Fichera, S. "Statistical design of variable sample size and sampling interval $\bar{X}$ control charts with run rules control charts with run rules", Int. J. Adc. Manuf. Technol., 28(9), pp. 966-977 (2006).

33. Li, Z., Luo, Y., and Wang, Z. "Cusum of Q chart with variable sampling intervals for monitoring the process mean", Int. J. Prod. Res., 48(16), pp. 48614876 (2010).

34. Lee, P.-H. "Joint statistical design of $\bar{X}$ and $s$ charts with combined double sampling and variable sampling interval", Eur. J. Oper. Res., 225(2), pp. 285-297 (2013).

35. Faraz, A. and Saniga, E. "A unification and some corrections to Markov chain approaches to develop variable ratio sampling scheme control charts", Stat. Pap., 52(4), pp. 799-811 (2011).

36. Mahadik, S.B. "Charts with variable sample size, sampling interval, and warning limits", Qual. Reliab. Eng. Int., 29(4), pp. 535-544 (2013).

37. Khaw, K.W., Khoo, M.B.C., Yeong, W.C., et al. "Monitoring the coefficient of variation using a variable sample size and sampling interval control chart", Commun. Stat.-Simul. Comput., 46(7), pp. 5772-5794 (2017).

38. Saha, S., Khoo, M.B.C., Lee, M.H., et al. "A variable sample size and sampling interval control chart for monitoring the process mean using auxiliary information", Qual. Technol. Quant. Manag., 16(4), pp. 389406 (2019).

39. Faraz, A. and Parsian, A. "Hotelling's T2 control chart with double warning lines", Stat. Pap., 47(4), pp. 569593 (2006).

40. Faraz, A., Kazemzadeh, R.B., Parsian, A., et al. "On the advantages of economically designed the Hotelling's T2 control chart with variable sample sizes and sampling intervals", Qual. Quant., 46(1), pp. 3953 (2012).

41. Faraz, A. and Saniga, E. "Economic statistical design of a T2 control chart with double warning lines", Qual. Reliab. Eng. Int., 27(2), pp. 125-139 (2011).
42. Mahadik, S.B. and Shirke, D.T. "A special variable sample size and sampling interval chart", Commun. Stat.-Theor. M., 38(8), pp. 1284-1299 (2009).

43. Mahadik, S.B. and Shirke, D.T. "A special variable sample size and sampling interval Hotelling's T2 chart", Int. J. Adc. Manuf. Technol., 53(1), pp. 379384 (2011).

44. Katebi, M., Seif, A., and Faraz, A. "Economic and economic-statistical designs of the T2 control charts with SVSSI sampling scheme", Commun. Stat.-Theor. M., 46(20), pp. 10149-10165 (2017).

45. Fallahnezhad, M.S., Shojaie-Navokh, M., and ZareMehrjerdi, Y. "Economic-statistical design of NP control chart with variable sample size and sampling interval", Int. J. Eng., 31(4), pp. 629-639 (2018).

46. Seif, A., Faraz, A., Saniga, E., et al. "A statistically adaptive sampling policy to the Hotelling's T2 control chart: Markov chain approach", Commun. Stat.Theor. M., 45(13), pp. 3919-3929 (2016).

47. Jafarian-Namin, S., Pakzad, A., and Fallah Nezhad, M.S. "A DEA-bases approach for multi-objective design of attribute acceptance sampling plans", Int. J. Data Envelopment Anal., 5(2), pp. 1231-1242 (2017).

48. Fallah nezhad, M.S., Jafarian-Namin, S., and Faraz, A. "Expanded fraction defective chart using cornishfisher terms with adjusted control limits to improve in-control performance", Int. J. Ind. Eng. Prod. Res., 30(4), pp. 477-488 (2019).

\section{Appendix A}

\section{Abbreviations and symbols used in designing SVSSI sampling scheme}

\section{ATS Average Time to Signal}

AATS Adjusted Average Time to Signal

SVSSI Three sample sizes and two sampling

ARL Average Run Length

VSS Variable Sample Size

VSI Variable Sampling Interval

VSSI Variable Sample Size and Sampling Interval

FA Full Adaptive

DWL Double Warning Lines

$n_{i} \quad$ Sample size $(i=1,2,3)$

$h_{i} \quad$ Sampling interval $(i=1,2)$

$W_{i}^{1}, W_{i}^{2} \quad$ Lower and higher warning limits $(i=1,2,3)$

$K_{i} \quad$ Higher control limit $(i=1,2,3)$

$p_{0} \quad$ The in-control defective ratio

$p_{1} \quad$ The out-of-control defective ratio

$r \quad$ The coefficient of control and warning limits 
$p_{i j} \quad$ The transition probability between the states $i$ and $j$

$d \quad$ The level of the shift in process

$F($.) The binomial cumulative distribution function

$\lambda$ The exponential distribution parameter

$B \quad$ The initial probabilities vector

$I \quad$ The identity matrix

$Q \quad$ The identity matrix

$V S S I_{n} \quad$ Three sample sizes and two different sampling intervals scheme (with different methods and assumptions with SVSSI scheme)

\section{Appendix B}

Procedure of computing AATS and ATS for SVSSI sampling scheme

1. Input $p_{0}, n_{0}, h_{0}$, and $d$

1.1. Calculate $p_{1}$ using Eq. (1)

2. Set values of $A A T S=+\infty$ or $A T S=+\infty$

3. Loop $n_{1}^{*}$ from $\left\{1,2, \ldots, n_{0}-1\right\}$

3.1. Calculate $W_{1}^{1 *}, W_{1}^{2 *}, K_{1}^{*}$

4. Loop $n_{3}^{*}$ from $\left\{n_{0}+1, \ldots, 50\right\}$

4.1. Calculate $W_{3}^{1 *}, W_{3}^{2 *}, K_{3}^{*}$

5. Loop $n_{2}^{*}$ from $\left\{n_{1}+1, \ldots, n_{3}-1\right\}$

5.1. Calculate $W_{2}^{1 *}, W_{2}^{2 *}, K_{2}^{*}$.

6. Similarly, loop $h_{2}^{*}$ and $h_{1}^{*}$ from $\left\{0.1,0.2, \ldots, h_{0}-0.1\right\}$ and $\left\{h_{0}, \ldots, 8\right\}$ respectively

7. Calculate $A A T S^{*}$ or $A T S^{*}$ using Eq. (2) and Eq. (3).

7.1. If $A A T S^{*}<A A T S$ or $A T S^{*}<A T S$, then

7.1.1. $A A T S=A A T S^{*}$ or $A T S=A T S^{*}$

7.1.2. $n_{1}=n_{1}^{*}, n_{3}=n_{3}^{*}, n_{2}=n_{2}^{*}, h_{2}=$ $h_{2}^{*}, h_{1}=h_{1}^{*}$

7.1.3. $W_{1}^{1}=W_{1}^{1 *}, W_{1}^{2}=W_{1}^{2 *}, K_{1}=K_{1}^{*}$

7.1.4. $W_{3}^{1}=W_{3}^{1 *}, W_{3}^{2}=W_{3}^{2 *}, K_{3}=K_{3}^{*}$, and

7.1.5. $W_{2}^{1}=W_{2}^{1 *}, W_{2}^{2}=W_{2}^{2 *}, K_{2}=K_{2}^{*}$

\section{Biographies}

Mohsen Shojaee is currently a PhD candidate of Industrial Engineering at Iran University of Science and Technology, Tehran, Iran and completed his MSc degree from Yazd University, Yazd, Iran. His research interests are statistical quality control, Markov models, applied statistic, and design of experiments. He is on the review board of a number of journals/conferences and has presented various research papers in different conferences.
Samrad Jafarian-Namin holds PhD degree in Industrial Engineering from Yazd University, Iran. He collaborated as a visiting scholar at Amirkabir University of Technology under supervision of Professor Fatemi Ghomi. He received a grant for $\mathrm{PhD}$ thesis by Iran National Science Foundation (INSF) and as a talented student by Iran National Elites Foundation (INEF). His research interests include statistical process control, time series analysis, reliability engineering, and generally implementation of six sigma methodology in application.

Seyed Mohammad Taghi Fatemi Ghomi received his BS degree in Industrial Engineering from Sharif University, Iran in 1973 and the PhD degree in Industrial Engineering from University of Bradford, England in 1980. He worked as a planning and control expert in the group of construction and cement industries and a group of Organization of National Industries of Iran during the years 1980-1983. In 1981, he founded the department of industrial training there. He is a currently Professor at the Department of Industrial Engineering at Amirkabir University of Technology (AUT), Tehran, Iran. AUT recognized him as one of the best researchers of the years 2004 and 2006 and as one of the best professors in the year 2014. Moreover, Ministry of Science and Technology recognized him as one of the best Professors in Iran for the year 2010, and the Academy of Sciences of Islamic Republic of Iran selected him as one of distinguished professors in 2018. He is the author/co-author of more than 480 technical papers and the author of six books in the field of Industrial Engineering. His research/teaching interests include stochastic activity networks, production planning, scheduling, queuing theory, statistical quality control, and time series analysis and forecasting.

Din Mohammad Imani is an Assistant Professor at School of Industrial Engineering (IE) of Iran University of Science and Technology (IUST). He researches on quality management, supply chain optimization, and financial engineering. He has worked as an industrial and public organization manager for 9 years. He has several experiences in implementation of IE techniques and published many papers in the related fields.

Alireza Faraz is a FNRS-FRS qualified researcher at the Quantitative Methods and Operations Management Department at HEC-Ulg, Liege, Belgium. His expertise includes multivariate statistical analysis, quality management, and business analytics.

Mohammad Saber Fallahnezhad is an Associate Professor at Yazd University, Iran. He received his BS, $\mathrm{MS}$, and $\mathrm{PhD}$ degrees, all in Industrial Engineering 
from Sharif University of Technology, Tehran, Iran under the supervision of Professor Niaki. He was a visiting researcher at the Karlsruhe University under the supervision of Professor Juergen Branke. Also, he is awarded a Silver medal in the 16th National Mathematics Olympiad in Iran and he is ranked 1st and 8th in the graduate national university comprehensive exam in System Management and Industrial Engineering in Iran, respectively. He is ranked 47th among all high school graduates in Iran. His areas of interest include dynamic programming, quality control, Bayesian inference, and operations research. 